\section{SB 335} .585 Copy 1
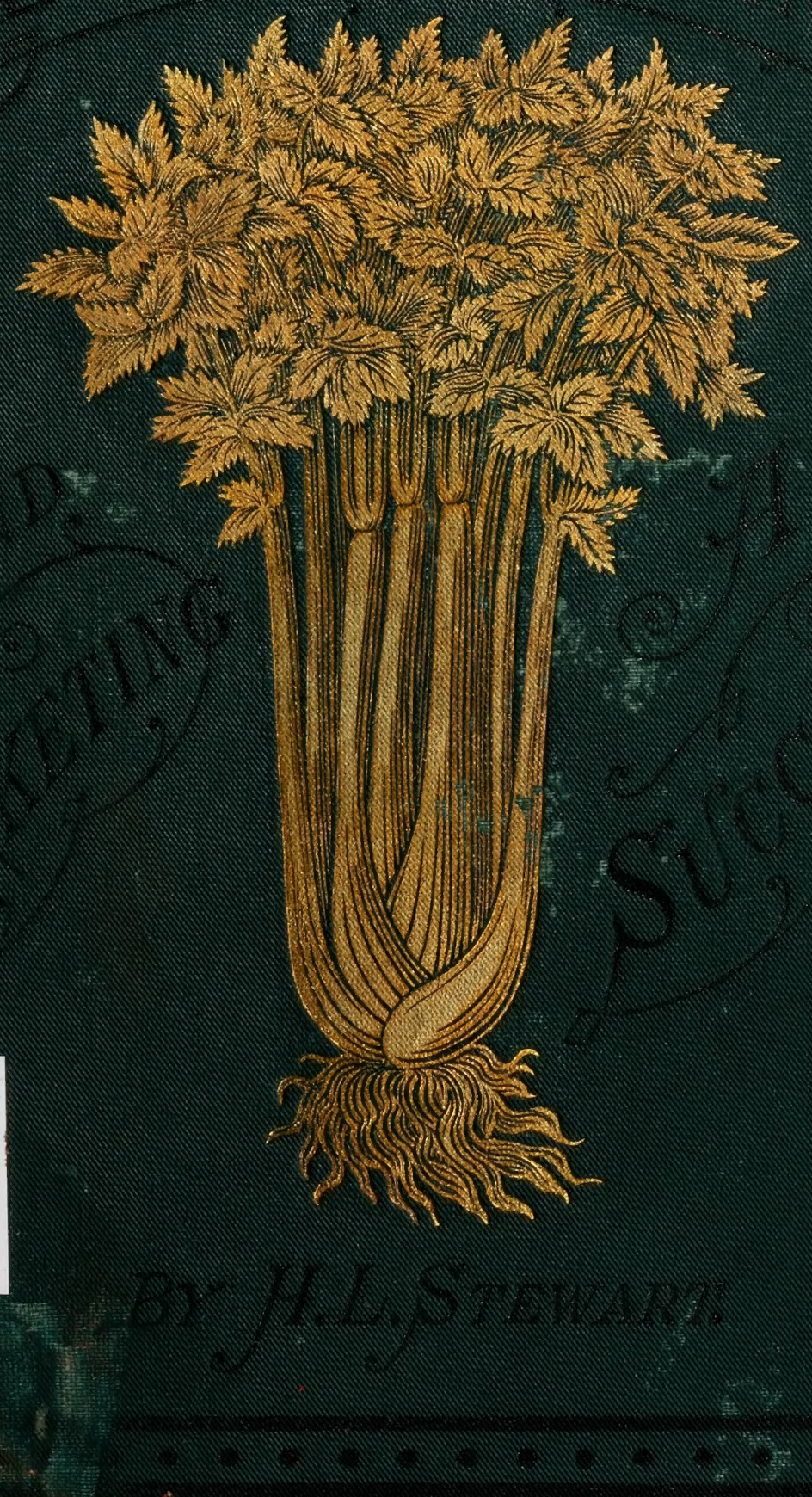


\section{LIBRARY OF CONGRESS,}

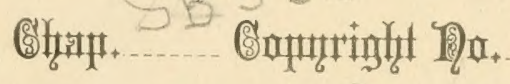

$$
\text { Shelf. } \$ 85
$$

UNITED STATES OF AMERICA. 








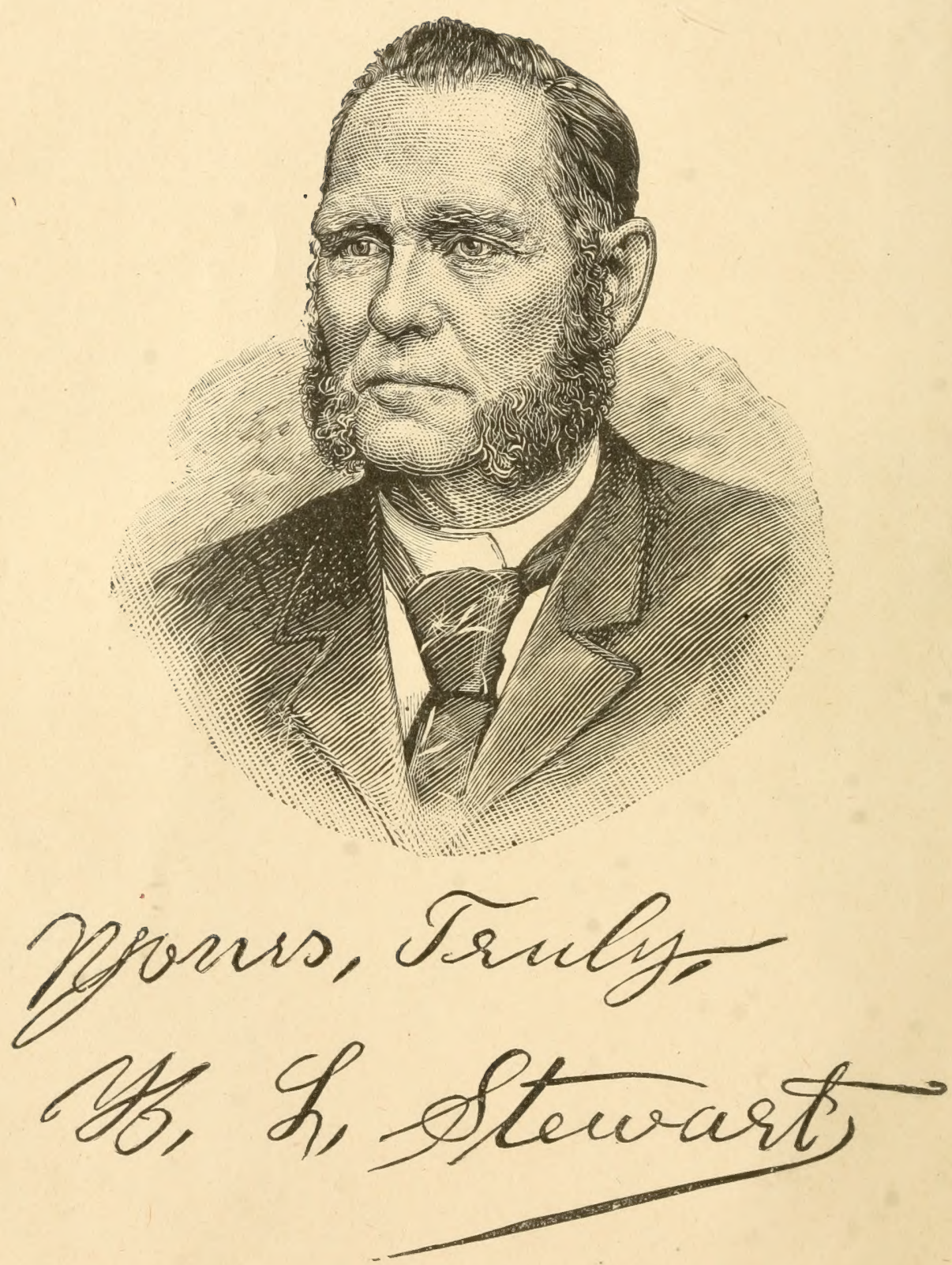


\title{
CELERY GROWING
}

AND

\section{MARIETING}

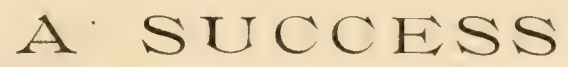

WITH PORTRAIT OF THE AUTHOQR

\author{
A L SO
}

\section{ILLUSTRATED WITH THIRTEEN PLATES}

\section{SHOWING NEW TOOLS AND APPLIANCES IN CELERY CULTURE AND THE CARE OF THE CROP.}

THIS IS THE ONLY BOOK EVER WRITTEN WHICH COVERS THE WHOIE PERIOD OF GROWING, MARKETING AND CARING FOR THE, CROP, WITH EXPIICIT DIRECTIONS.

BY

HOMER L. STEWART, Originator of Stewart's Prairie-Side Celery Growing. TECUMSEH, MICH. 
Entered according to the act of Congress, in the year 1891, by HOMER I. STEWART,

In the office of the Librarian of Congress at Washington. 


\section{DEDICATION.}

\section{TO THE PEOPLE OF THIS GRAND UNIVERSE}

Wheresoever located, without distinction as to size, strength,

age or sex, who by a well directed thought or act shall

contribute to the death of the day of cruel

wrongs now perpetrated upon humanity ;

whereby the tears which now stand upon the pale cheek of sorrow and want shall be dried; and the abundant supply of earth's richest harvests more evenly divided by

a people and an eternal principle of right which shall teach every person to mind his own business, and all earn an honest living :

THIS VOLUME

IS MOST RESPECTFULLY DEDICATED

BY THE AUTHOR. 



\section{PREFACE.}

After reading this treatise through once, you will have something of an opinion of your own in regard to it. I certainly have endeavored to make it plain. My spare time from the care of $\mathrm{my}$ celery industry for the past two years has been spent upon this work. There is not an item in the book but what can be relied upon as giving the same answer as recorded here when surrounded by the same conditions and manipulated in a similar manner. They have all been demonstrated. I hope you will read the preface entire first. In this book is noted my own practical experience in celery growing and marketing. Not a phrase has been borrowed from any article ever written by others upon this subject. Now believing as I do that what has been done can be done, I give some figures in my own business, which I otherwise would not have given, not as a boast, but simply recording a fact in a business pursuit for the benefit of others 
that they may occasionally "See a footprint in the sands of time" and take courage anew.

As you commence studying this book, a short history of celery is noticed at first; then the different kinds of soils, which are hest, how to prepare them so you can reasonably expect a cerop: the kinds of celery to erow for the fiamily, also the kinds to grow for market: how to make a hothouse or bed, how and where to get the seed, how and when to sow it. early and late; how to tit the grround for the plants; how to care for the plants betore setting, how and when to sed them, how to care for them after heing set; how to blanch them; how to grather, wash, bunch, tie and box: how to market, get all your geods are worth, and your pay; how to find huyers that want your celery, aud how to keep them; how to build the storehouse, and how to store celery away for the winter, and when to gather it in the ditrerent latitudes. Also all tools and appliances for growing, and to facilitate handling and (aring for the crop, together with thirteen cuts illustrating how to make and use them, as there are reveral which you cannot as yet buy alpeady made.

In raising just for home use, there are many things which can be clispensed with, but in growing for market, in order to entertain a reasonable hope of success, you must be prepared in both knowledge and equipments to measure arms with the very best growers in the field.

I think the cuts all show plainly, so you will be able to make them. Some are very valuable and you camnot afford to try to get along without them. The pulverizer to fine 
the soil; the wheel which punches the holes for the plants; the washing rack, with its style of work; the rubber tying box with its foot lever; the rope crates for bandling without bruising; the perfection of the banking plow; the knife as attached to the plow for cutting the celery out of the ground, thereby saving one-fifth of the help from the way of taking it out with the spade or fork: are all of $m y$ own device and new in celery culture. Those who do not have them cannot compete in price or perfection with those who do.

Taking the difference all in all between the mode usually pursued by celery growers and that as laid down in this treatise, it is fully as great as the difference is in harvesting between the old cratle and rake and the self-binder. When I commenced rasing celery I left no stone unturned in my endeavor to learn how to get better results than were being realized by growers then. As it rusted, and was liable to rot in warm weather as it approached ripeness, the consequence was that it was harvested green to sare it, and upon the whole it was pretty tough and poor. I watched the horticultural papers for items to help me out of the dark, searched high and iow, far and near, for a book of instructions, but was not able to find one, and never have, to this day, been able to find one worth mentioning. I have bought a sample of everything I have ever seen advertised, which at the best has been some little pamphlet, very meager, with no practical information except what any one engaged in the business could not help but learn the first morning before breakfast. I could have well afforded to have paid a few thousand lollars for a book containing the information 
which this one does, as it would have enabled me thereby to have saved a net of six or seven thousand dollars per year for the first three years, which I spent in learning just what is now practically shown up in this work. I appeal to your judgment to sustain me in this assertion.

Here are the facts in the case: In February, 1883, I bought one hundred acres of land at thirty-one dollars per acre, three miles from town, fifty being upland and cleared, the balance a swamp covered with willows, wild grasses, small poplars and elm trees. I cleared thirty-four acres and raised one acre of celery per year for the first three years, the fourth fourteen, the fifth twenty, and for the last three years thirty-four each year. Now for the result: From this acreage as given, for the past five years, closing with $1890, \mathrm{my}$ gross receipts from celery sales have sixty-seven thousand dollars, with a clear cash net of forty-one thousand dollars over all expenses. (The matter of transportation has not been brought into account here, as the buyer has always settled that at the other end of the route, I selling celery free on board car.) This is an average for five consecutive years, through favorable and unfiarorable seasons.

My fourth year, which was in 1886 , I sent ont my first fine celery, and I soon became convinced that it was at higher grade than had ever before appeared in the markets, from its ready sale and the high praises of it which I received from my patrons. I now concluded to show the experts in horticulture what had been accomplished. I there- 
fore sent sample boxes to a great many throughout the different States. They acknowledged the receipt at once, paying it the highest compliments in every instance. The following are samples of hundred of letters received:

New York, Nov. 11, 1886.

Mr. H. L. Stewart, Tecumseh, Mich.

DEAR Sir: Through your kindness we have to-day received some specimens of White Plume celery; very beautifully grown and deserving of the highest praise. We would like to know what you would charge us for a dozen boxes same as the one sent us, which we wish to use here in the city for adrertising purposes. If you will also describe your method of culture we will be obliged.

\section{Yours very truly,}

Peter Henderson \& Co.

Mr. Henderson was very much pleased to be able to show up this .elery, as the following notes would indicate. In his seed catalogue of 1887 he says: "The celery IIr. Stewart sent us was beyond all question the finest we ever saw, and was sent by us to Delmonico's restaurant in this city, where its exhibition created a furore." Here follows what several of those high-priced hotels in New York City thought of the second lot, sent Nov. 15, 1886, which Mr. Henderson speaks of wanting to show in the city. 


$$
\left.\begin{array}{c}
\text { Fifth Ave Hotel, } \\
\text { New York, Nov. 19, 1886. }
\end{array}\right\}
$$

The celery sent hy you yesterday has been received and tried. We are pleased to say they are the most beautiful specimens we have ever seen.

\section{Hitchcock, Darling \& Co.}

\section{Hotel BRUnSWICK, New York, Nov. 19, 1886. $\int$}

The box containing celery received, and in acknowledging we beg to say that it is the best we ever saw, and would gladly know where to purchase the same.

$$
\text { J. B. Wistar, }
$$

Steward for Hotel Brunswick.

$$
\left.\begin{array}{c}
\text { Murray Hill Hotee, } \\
\text { New York, Nov. 19, 1886. }
\end{array}\right\}
$$

The specimens of celery are really beautiful, and show an advancement in the cultivation of this regetable that merits more than ordinary praise.

Hunting \& Howard.

$$
\left.\begin{array}{c}
\text { Hoffuan Hodse, } \\
\text { Nov. 20, } 1886 .
\end{array}\right\}
$$

We are in receipt of the box of celery, and find it the finest we have ever seell. A portion of it was served at a 
special dinner of fourteen covers and receired the highest encomiums by the guests who ate of it.

$$
\begin{array}{r}
\text { Very truly yours, } \\
\text { J. A., }
\end{array}
$$

Sample buyer for Hoffman House.

$$
\left.\begin{array}{c}
\text { Gilsey House, } \\
\text { New York, Nor. 18, 1886. }
\end{array}\right\}
$$

I am in receipt of a sample box of celery from your house, and think it the finest I have yet seen.

A. D. Hayner, Steward.

It has also graced the table at the White House, as the following letter will show:

Executive Mansion, Nov. 26, 1886.

Mr. H. L. Stewart, Tecumseh, Mich.

DEAR SIR: Your pleasant Thanksgiving remembrance by a box of celery was duly received, and I beg to assure you of my appreciation of your courtesy and of the excellency of the product.

$$
\text { Very truly yours, }
$$

Grover Cleveland.

Those New York hotels noted above buy the finest productions that the earth produces, regardless of the money cost, as their patrons bave got the cash to pay for 
that kind of fare, and their opinion is worth something. Hence every grower of celery who has the ambition to sell at the top of the market, so as to get the best remuneration for thought and labor, will be pleased to know that this treatise contains the necessary information, as a guide to the production of celery which from the evidence above given has found such noted favor with the public. I am fully persuaded that to follow the course as laid down here (until you are sure you can do better) is the beginning of wisdom. Learn your business well, then start in with a determination to succeerl, and you will, as success does not come by chance.

July 1, 1891.

'THE AUTHOR. 




\section{CONTENTS.}

History of Celert, . . . . . . . 25

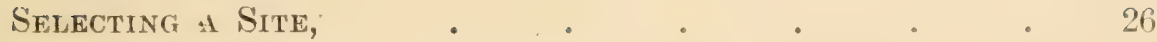

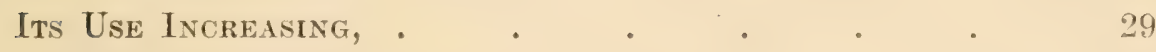

Success in a Nutshell, . $\quad$. . . . 30

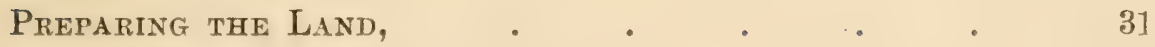

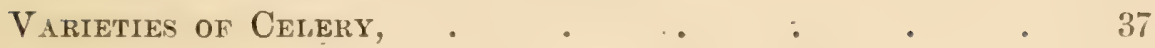

Making a Hotbed and Sowing Seed, . . . 40

Sotwing SEed IN Open Air, . . . . . . . . 42

Getting Ready to set the Plants, . . . . 44

Sectioning and Pratting Land for Convenience, • . 46

The Wheer, its Constructiox and Use (see Cut No. 2), . 49 
Taking up, Separating and 'Serting tme Plants, . . 51

Chring for Open-hir Seed-beds, . . . . 59

Care of Celery after Setting, . . . . . 60

Material Used and Preparations fol Blaxching, . 64

MAKING THE Hooks, . . . . . . 66

Getting the Bohrds along the rows, . • . 69

Putring the Boarde in Position for Blanching, . . 70

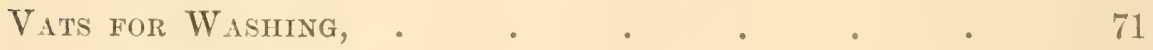

Preparing for Harvesting and Matiketing witere there is

a Crop of Twenty to Forty Acres-Water for Wash-

ing and Necessary Buildings, . . . . 71

How to make a Box in which to Buxch axd Tie Celery, 79

Alloting Space to Tyers, . . . . . . 79

Adjusting for the Foot Lever, . . . . $\quad 80$

Beauty of Rope Crates (see Cut No. 10), . . . 84

Their Construction, . . . . . . . . . 84

Passing the Bunches into time Packing Roon, also Finish- 
Having the Packing Room ICed, . . . . 88

Buthding House for Boxing Lumber, to yake tite Boxes

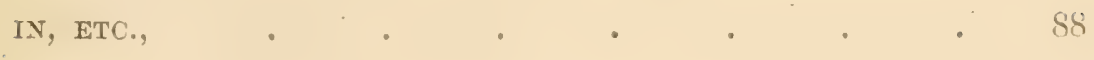

Selecting and Preparixg Lymber for Boxes, . . 91

Boxing Cemeri, . . . . . . . 91

PACking Room should be Frost-proof, . . . . 92

A Tool-house Needed, . . . . . . . 94

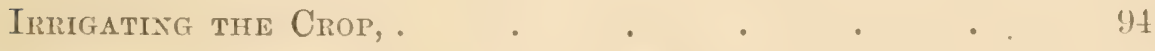

Reviewing the Celery Field and the Workmex, . . 99

Commencing the Harvest, . . . . . . 101

Mirketing the Crop, . . . . . . . 107

Theing a Review, and making an Advaxce aflerwards, ind Gettixg some Storehouse Mlater 1aL, . . 116

Banking with Eatrh for Blanching. . . . 119

The Constructiox of Shovel Plow and its Use, . 120

The Tine for Binking Winter or Store Celery, . . 124

An Attachment for a One-Horse Plow to cet off tine

Roots, and how to use it (see Cut No. 13), . . 126 
HOW TO HAXIHE THE HEAM THAT ARE TO BE STORED, . 130

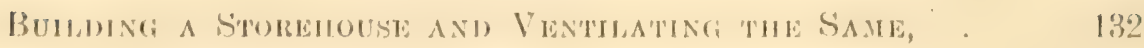

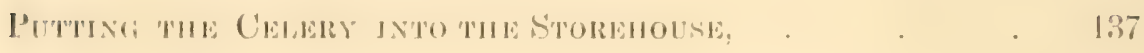

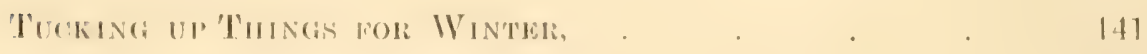

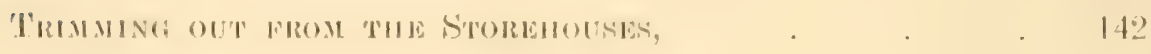

MAKING THE FINA, CLILAN UP, . , . .

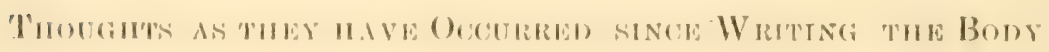

oF THE Воок, . . . . . . . . 145 


\section{ILLIISTRATIONS.}

Potriratt of Autilor,

PAGE.

1. The Pulverizer, . . . . . . . 沙

2. Winel for Punching Hoiss, . . . 47

3. Setting the Plants, . . . . . . 5:;

4. THE SCrAper, . . . . . . . . . . . .

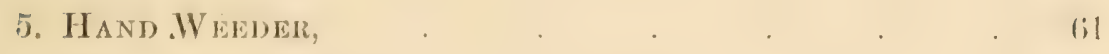

6. HoOkS FOR BOARDS, . . . . (iT

7. WASHING RACK, . . . . . . . .

S. Tring Table, . . . . . . . . . . . . .

9. Bunching Box, . . . . . . . 81

10. Rope Crate, . . . . . . . . . . . . .

11. Carrying Cememy in Crate, . . . . S!

12. Banjing Plow, . . . . . 121

13. Plow hor Cutring Roots, . . . . 127. 

[Ploase read the preface first, as you cannot fully understand the book without it.]

\section{Celery Growing and Marketing.}

\section{HISTORY OF CELERY.}

CELERY was introduced into this country from Europe, that place having been its home; it grows wild there, in saline soils, usually upon low lands, upon the edges of ditches and brooks; the stalks are hollow, with a bitter acrid taste, but now after years of cultivation it is so much changed that its flavor becomes expuisitely agreeable, and it is regarded as a very wholesome diet

Through cultivation and time its stalks have become solid in the main, yet some varieties have a tendency to revert to their original hollow condition. As we study the history and natural habits of this plant, it will aid us very materially in selecting a suitable soil, location, and preparation for its successful cultivation. Nature directs the way, si) with care and a painstaking search we may fol- 
low; even though afir off, it is better than to be entirely astray.

\section{SELECTING A SIT'F.}

The peat lands, which are so rommon in many of the States, are without doubt the choicest lociltions upon which to grow celery for market, as it can be quickly workel, and done so easily, after you once know how, and at such a fine profit for your thought and labor, mpon lands that hat ve been an eycsore for years upon thousands of firms all overeme country. They have been known as waste lands, swimps, mire holes, gound for nothing only to hold the world together, and hardly that, usually corepenl with a growth of hushes, weeds or coarse gratixs uf some kind. Grolden-lod with its bright yellow blossoms freyuently his entire control; hut these lespised places have never contributed one dollar as profit to the firm, simply becalise you have nut possessed the key with which to mulock the storchouse of wealth and protit which hare lain there in a latent condition, "Lo, these min!y" years." Now some morning awake up! resulre to give this much despised swamp) a fair chance to contribute, and I assure you it will respond most nobly. I know, for I have tried it.

Some of these lands have shallow water standing upon them a part of the time. Such must be 
drained; in fict they all need ditching to some ex. tent, but not too deep, or you may get it too dry, in a dry season. By the way, such lands, when reclaimed, will grow almost any crop (except the cereals) that will survive the late and early frosts that are inciclent to such low lands in this latitude. When I was subduing mine for a first crop, I grew corn upon twelve acres, had one hundred and twenty bushels per acre, and a frost hurt it some in August. The water stood within twelve inches of the surface when plowed in the spring. But excuse this digression; we are now upon the celery theme, and must stick to the text.

In case the land has willows or any small trees, it is best to grub them right out and clear it so you can plow it well, and a small patch of celery, four or six acres, will return you a larger net profit than your whole farm beside, even though you have a full onc-quarter section. There are thomsands of firm; with from one to twenty $O l^{\circ}$ more acres upon it of this kind of land, and a mortgage besides. Now, without any joking, it usually takes cash or its equivalent to get rid of those obnoxious things, yet one or two crops of celery will do wonders in that line. In short, the mortgage is off, the land you still have. It has waked up)! It is doing its duty grandly sinee youl liare given it a chance, and you will nerel. want to get 
rid of that, as you have now found out its value, and what a true friend it has been in your trying hour of need.

These peat beds are the residue of decomposed matter, grasses and weeds, all formed right there when it was a lake, consequently it is all vegetable matter, full of nitrogen in a latent condition. They are very easily worked, and at much less expense than common lands, butrequire different treatment, which will be particularly noted farther on. Almost any tract of low, level land can be utilized for celery-growing; level, because it will not wash rluring heavy rain storms, and low, because such places retain moisture much longer in dry times. The Middle States have more lands adapted to celerygrowing than either the Eastern, Southern, or Western, although there are some fine locations in all the States and Canada. The dry windy climate of the West is somewhat against that section, although that is being overcome by the system of irrigation. All the Gulf States have fine lands for celery. Tamarack swamps make good places in time, but they must be cleared several year- hefore they can be utilized for that purpose; as the peat is too new, consequently coarse, it must rot down some first. Black ash and elm swamps are usually much richer, naturally, than any of the peat beds, as the soil in the black ash is a leaf mold; that is what I 
call muck land, and there is usually a subsoil of clay within a few inches of the surface, which so completely holds the fertility from getting away that they can be made to produce one of the best of crops, in case the subsoil is deep enough so the plow does not turn up enough of the clay to make the land stiff and hard.

What has been said so far applies more particularly to growing celery on a large scale, or in other words, "for market." But we desire to consider the growing of this precious article of diet in all of its bearings and relations to the human family. Hence I say every farmer can grow it, in fact all who have a garden, he it high or low ground, clay or sand, by making it rich enough and keeping it well watered. It is very nice indeed, and labor well expended, to grow each year a fow hundred heads for the family. It causes you to sleep more soundly, and cuts down the doctor's bill, etc.

\section{ITS USE INCREASING.}

Eight years ago it was a rare sight to see celery growing in this State, outsirle of Kalamazoo, or to find it upon the table of the farmer or working-man; it was considered a great luxury; but times are changing. It is now being considered a necessity for everyone, and not as in former times indulged 
in only by fancy hotels and a few private families hero and there.

Just as soon as it is produced in quantities suf ficient to go around and supply the wants of the whole country, and at a price within the rearch of all, it will be found upon every table, as it ought to be. The demand now keeps ahead of the increased production. It will be years, if ever, before the whole country is fully supplied.

Take for example the little village of 2,200 inhabitants, here where I live: it required only one acre of celery eight years ago, now it takes the growth of twelve acres to satisfy its demands. It seems to be advisable for all who are engaged in the celery industry to supply their home market first, then in case of a surplus to establish a trade with your nearest city market.

\section{SUCCESS IN A NUTSHELL.}

Up to the year 1886, nearly all celery was blanched by being banked up with the earth from between the rows. This does well as the cool weather of fall approaches, but in warm weather, and especially warm and wet, just as soon as it approaches ripeness and readiness for use it becomes very tender, and will rust or rot through the contaminating influence of the moldy earth. This is sure to be the case where the soil rests against the 
stalks, especially if the celery is of a high order and tine-grained quality.

Tile and papel had been somewhat used on a small scille, but at the date above mentionerl the use of boards for blanching had their advent, and most admirably do they answer the purpose. The appiances, paraphernalia, and their application to celery-culture shown in this book, are of my own designing, and have all been brought to the front within the last five years from a necessity to produce a high grade of celery.

My first three year's' crops were very nearly failures, I, like every one else engaged in the business, not really knowing how to handle the crop so it would not rust and rot as it approached ripeness. While growing my third crop, however, after it was too far gone to save much of it, I thought I had discovered where the secret lay in saving the next year's one. Acting accordingly, it proved a grand success, since which time light has shone brighter each year. The theory has proved eminently successful and profitable, and the science of the whole practical, successful experiences, all having been thoroughly demonstrated, are recorded in this book.

\section{PREPARING THE LAND.}

Now we will prepare the land for first crop. Take low, wet lands first. In case there is no visi- 
ble way of draining the swamp without cutting a deep ditch through the bank or rim that holds the water in, it is a good plan to prospect for a gravel outlet in the bank, in the event of your heing in a gravelly locality. Many of these peat becls are simply cisterns; the washings from the hills have formed a sedimentary deposit that holds the water.

Cut well into the bank of gravel for an outlet, then dig your ditches and drain into it. Thirty inches is deep enough for the ditches. Do not get it too diry. Always bear in mind that celery delights in frequent drinks. In case of the ordinary level lay of such lands, one ditch every forty rods is sufficient, as peat lands are very porous, hence water passes through rery readily. It is best to have open ditches at first, then you can tile if practicable after you see that the drainage is all right.

Clear the land as for any other (rop, only have it more free from roots of shrubs, chunks of wood, etc. In casse grass, will or time, is growing upon it, that must be well turned under one season in advance of the setting it with celery. But in cise it is covered with small trees, willows, or brush of any kind, clear it well, and it is as good the first year for a crop as ever. Plow all peat lands eight inches deep.

Land that will produce 80 bushels of corn per acre will want to be fed with twenty two-horse 
loads per acre of good stable manure, grain fed, and not burned by heating in piles. Spread as drawn, in fall, winter or spring; fall and winter are best, as the elements of fertility get well into the soil by spring, at which time plow under. In case your manure is poor, it will require more. Should it be much strawy, rake it well into the furrow in advance of the plow, or it will beliable-to interfere with the setting of the plants. After plowing, if the land is somewhat uneven in short jogs, go over it with a leveler, made with handles, after the style of an old-fashioned road-scraper.

Now, sow broadcast five hundred pounds of refuse salt and fifty bushels of unleached ashes to the acre, or in place of the ashes, five to ten hundred pounds of kainite, sometimes called "German Salts." You can get it usually of local fertilizer dealers at about $\$ 15.00$ per ton.

Now is the time to make the land fine like a garden. A disk harrow is a good tool to cut it up with, in case it is soddy. Peat lands when new are lumpy, and I know of nothing for pulverizing them equal to the home-made tool shown in cut No. 1, called the pulverizer.

Take oak plank, five feet long, eight inches wide, and two inches thick; fasten a chain to the front edge to draw by. Now bore auger holes 
two inches in diancter through the plank, drive oak pins through from lower side, wedge firm, fix poles (as cut shows) eight feet long, cnamfer lower side of pole in fiont of hole, so the front edge o: the plank (an rise over the lumps when being drawn. I think it will commend itself to your favorable consideration at a glance. This tool will help to cover up the fertilizer, level the land and powder the lumps.

There are parties who deal in ashes. I here give the name of one such firm: Munroe, Judson \& Strop, No. 3:2 Arcate Block, Oswego, N. Y. They furnish by the car load.

I will say before going firther, that in case you are short of stable manure, you can fill in with dried blood, which can be had for about $\$ 35.00$ per ton, in "ar lots, of the North-Western Fortilizer Co., of Chicago. That which looks dark-brown, is not good ; it has been burned while drying. it down. The red, looking like fresh ground tim-bark, is good. Sow same as rommercial fertilizers, ten to fifteen hundred pounds to the acre. Manures sold under the head of commercial fertilizer's have never produced near so fine a crop on pat land for me as stable manure.

Now agrain: there are lands that will grow fine celery, such als sand loanss and clay loams, 


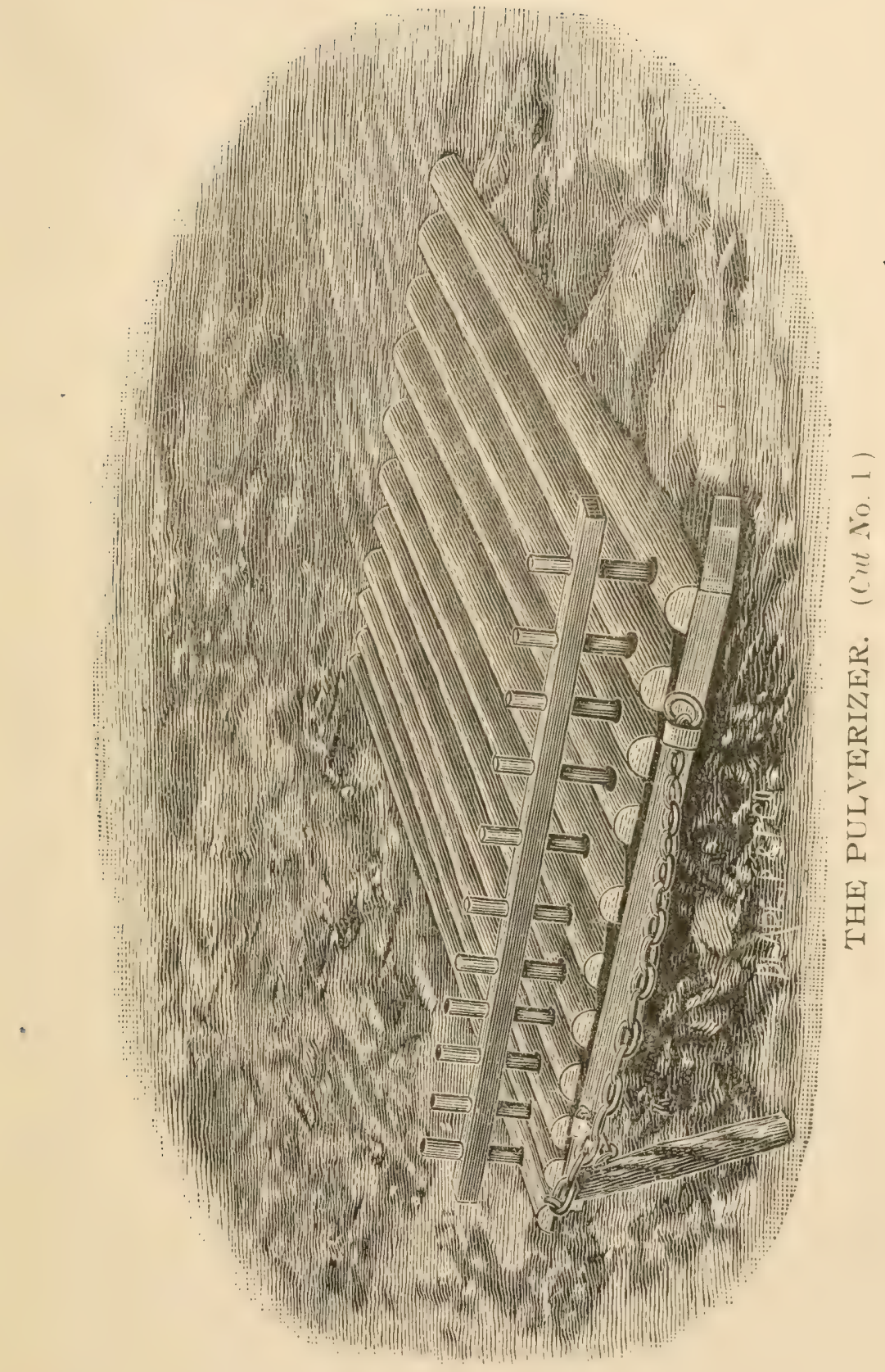



but be sure and have it so thoroughly enriched that it will be mellow, like an ash heap, and well fined; then in a wet year you can grow a fine crop, but in a dry year it will suffer, and in no case can it be grown so easily or cheaply as upon the muck lands, or peat linds. In my opinion, the peat land stands first, the muck second, and the clay and sand loams third. Yet with any of the three grades, a person that understands his business, under favorable conditions, aan do wonders.

Exercise care, be painstaking in all the details, do the work the day it should be done, and do it right. A sloven ought not to expect an abundant harvest. Celery must have growth, crispness and flavor. Try to inprove on each past crop. It nearly always can be done. Bear in mind that it is a dull scholar that does not learn some new and good thingss each year. "Excelsior" is the watchword of to-day, and those who tarry too long in the rut, or look back, waiting for help from some miraculous source, will "get left."

\section{VARIETIES OF CELERY.}

There are twenty-five or thirty different names for celery. There is a wide difference in some of the celeries, both in general appearance and merit. When I first commenced producing 
celery, I purchased secd by every name that I could hear of, and that gave me an opportunity to test all kinds, and so decide which was best for my ground. The plan is good for everyone.

The carliest variety, and the one that sells best, is the White I'lume. Next is IIenderson's Hilf Dwarf, Golden Dwarf, and Golden Heart. For late crops, to stand the cold and to store for winter use, the Duston Market leads the list. It hias the best flitror, and is nore tender than any other kind. Next in ordm come White Walnut and Perfection Martwell, buth of which are good. Then comes Henderson's New Rose, a pink variety, one of the best of winter keepers, a choice rich flaror, but will not sell in the market, as nearly everyone is prejudiced against pink or red celery.

There is still another variety worth mention. ing-that is, the Golden Self-blanching. It is a very yellow sort and quite attractive in appearance when ripe. It seils well, but hals a poor farror, and is quite liable to rot at the heart as soon as ready for use.

Different varietius vary in different localitics, in vigor, solidity of stalk and profit. Therefore get a packet of all kinils fir a test, but have your princiral crop of the kinds I have named and you will not be astray. 
The White Plume originated on the celery grounds of the lite Peter Henderson, of Jersey City. He found one head, and grew seed from it about the year 1875. Being such a distinct raricty and so very pretty, it was universally tested, lut in a few ycars almost given up as wanting growth and flaror, or as being unprofitalile. That wis one of the linds I tested when commencing the business, and found it tie must profitable rariety ever grown. The present style of handling it was dereloped here upon my grounds, since which time the markets have been all alive to git hold of it, as it stands at the head in the markets of the world. When in its beauty and prime it is a rery hlelicate sort, and will not lieep very well later than Christmas.

You can send for sech catalogues which will show to you the varictics and low to gect them. There are scores of dialers; I here give two: Peter Henderson \& Co., Cortlanul strect, N. I., and A. W. Livingston's Sons, Columbus, Ohio. Both are groul reliable firns. Semul in your niane, asking them to send you seerl catalogu, and they will do it in the hopeot getting ?our custom. Oreler secd su as to hare it ia February. There areseed houses, in fact, in every State. 
MAKING A HOTBED ANI) SOWING SEED.

It is not necessary to go to the expense of building a costly house to grow carly plants in. In carly winter cover over a few squilre rods of ground, such as would make a good seed-bed, with barnyard manure, two or three fect deep, so that the ground camnot freeze. Then aloout the first of Narch, pile this manure off the lind, also take enough surface dirt to corer your hotbed manure five inches deep. Set boards erlgewise where you have taken the earth to enclose your bed; liold them in position by stakes and nails. Now fill in fiftcen inches decp with grain-fed manure, with some litter mixed through it, either from horse, sheep or hog; pack solid, and there will be good heat generated to give you fine plants large enough to set in sixty days. After packing put on earth five inches thick, tread down.

Now sow the seed, either in drills six inches apart or broadcast. Rake in, and tread down again if the soil is peat, not if any other kind. My experience is in filvor of broadcast sowing ; can get moreand stockier plints off same groumd. Take a half-pround baking powder can, punch a fin small holes in the licl, fill with seed, mark oft a few square feet on the dirk ground, so that the seeds will show. Now shake it over the same as a pep- 
per box, and count the scels upon a square foot. Have 150, but after they come up thin to 100. Trhere the bed is solid it does not hurt to walk on it with rubber's on (or any broad-soled foot wear) for thinning, weeding, etc.

Bear in mind to have your sash made and in readiness to cover as soon as seeds are sown. Malie the bed to fit the sash. A handy size is three by six feet. Bank around the bed to keep out the cold. The sash should slope towards the south a little, say at the eaves six inches above bed, at upper end 18 inches. After the plants come up, put a themometer inside. Don't let it get above 90 degrees. Block up the sash to let in air. Keep well watered, and when four inches high shear half down with sheep-shears; it makes them root heavier.

Peat soil is best of all for seed-beds, as it will not get hard. Then comes muck as next best, which, however, is greatly improved by adding one-quarter sand well mixed together. Do not pack this soil after the seed has been sown.

This style of a hotbed will do very well for a start, but firther on I will give instructions upon a larger scale which will be utilizing one of the storehouses for that purpose after the winter celery has all been trimmed out. It will answer the purpose well. 


\section{SOWIYG SEED IN OPEN AIR}

Hare ground leveled down in the fall in three or four different parts of your colery field, which are the must free from weed sechls, also where it holds moisture well. As som als the frost is out of the surfice in April, som one bed ; in eight dias another. Mare all sown by first of May. By so doing you will havdly fail to be assured of having an abundance of plants. Be sure to roll your seedbeds after soming and raking in lightly. High gravel, clay or sandy land raises very poor plants, unless inmensely rich and kept wot.

Keep hals free from weeds and keep tops mown off with common grass seythe. Always rake oft the eut leares with fine ralke. In case the weeds are rery thick when the plants are small, you can use a board twelve inches wile and sixteen foet long to work on. Keep turning board over as you adrance twwards weels. Board does not hurt plants. Sow three pounds seed per acre. One acre of good secedbed will set eight to twolve acres of ground.

I have been able to get early plants by using cotton eloth instean of glass, from seed sown first of April. Fix boards around bed the same als for glass, tack eloth on top (commun yard wide muslin, thin). 
There is a growing demand for early celery. A great many people use it early and late, and all the time when they can get it, and momm leecause it is not in the market every day in the year. Hence the carlier you can have it ready in summer and the later you can keep it in winter, the longer the season and the greater the profit. Farther on you will find explicit directions low to build a storchouse into which celery is put upon the approach of cold weather in the fill, and trimmed out in winter for the market. This makes a fine place for a hotbed by taking off the roof from. the south side and putting in its place glass. Then in case there is need of it a stove can be put in to help kecp it warm. Enough fine carth can be put in before it freces in the fall for seed hed when ready to be used. There is considerable earth taken as a matter of course upon the roots of the colery when it is stored. When the celery is trimmed out pile the waste stalks, leaves and roots so they will rot down and be ready to mix with the soil. By having a pipe come from your windmill underground so as not to freeze, and up inside of the storelouse, terminating in a hydrant, the sceel bed can be watered nicely by attaching a hose with a rose nozzle.

The plant beds over the field can all be plowed and worked in as you come to them if the plants 
are out; if not, as soon as the bed is free come back, fit the ground and mark out the rows to mate or conform to those alrearly sct, either full or parts of rows, taking some pains when selecting plants for the seed-bed to get large, strong ones. As they will be later set out, they need to be larger to catch up with their neighbors. It can all be done so as to show up an eren field by using a little head work. I have known plants to be a perfect failure on one or two beds in a ficld and others in same field to be very fine. Hail storms, droughts, etc., are very destructive when they reach celery fields.

\section{GETTING READY TO SET THE PLANTS.}

As the first of May approaches, the land to be set with celery needs to be made ready. A set of soft-ground shoes are needed. You can make them yourself from a piece of $1 \frac{1}{4}$ inch plank, eight inches square; cut holes for the callis, then bore a $\frac{3}{8}$-inch hole each side of the hoof, through which put a loop of $\frac{3}{8}$ iron rod with threads cutupon both ends, also burs; slip the loop orer the hoof so it will set near the upper edge of the hard part, then screw up so as to hold it in place. A horse will walk easily now where he would mire or flounder without them. L. Brigham, of Decatur, Michigan, manufactures iron soft-ground shoes at one dollar apicce. I have a full set. They are just the thing. 
Now, in case your land is not thoroughly pul. verized and fined, or is grassy or weedy, go orer it with a common harrow or a disk harrow and pulverize just according to the needs of the case, then roll down with a heary roller. Now the ground is in condition and the plants are ready for setting:

There is one more implement needed at once, that is; a marker, made similar to one for corn This difference, howerer, obscrve: have the mark ing tecth nearly perpendicular, and made so they can be changed from a three-foot to a four-foot gauge. Where you are to blinch with boards, tile, or paper, mark light, so as to set the plants upon the surface, and three feet between rows is about right. To blanch with earth they must be four feet apart, and trenched about four inches.

The trenching can be done while marking. Take a strip of board, adjust upon each sicle of each tooth, leaving the tooth projecting two inches below the lower erlge of the board. Screw fist to the tooth, also screw a stay on the back of the flanges to make strong. Now you have something like a shovel-plow, and so light it is easily handled. Go in each row twice; let the horse walk each time in last row. It makes a very nice trench to set plants in for earth bank, and at the same time throws the dirt well back from the row. By bearing lown 
or easing up you can make a uniform trench. Commence upon that part of the field where the highest and driest ground is, so as to get the plants in there early, before the dry weather comes on.

SECTIONING AND PLATTING LAND FOR CONVENIENCE IN BLANCHING.

For the first row set a stake at each end just where it is to be, and drag a chain as a guide for the marker. In case there is not much danged from weeds coming on, mark off all you calculate to blanch with boards, tile or paper. Leave a wagon road through the center of your field crosswise the rows, where the rows are more than thirty rods long, as a convenience for getting boards to the celery and harvesting. Twelve feet wide is enough. I have 125,000 feet of lumber that blanches about twenty-two acres of my thirty-four acres each year, and am through with the boards in time to use them for my winter storehouses by first of October, some a little before.

A large amount of labor can be saved by the following plan: Divide your rows off in sections of four rows each as far as you can set two rows of each section in May. After the last day of May, three rows to the section is enough. That is, set the first row marked, then skip the next three of that section. Now set the first row of the second 


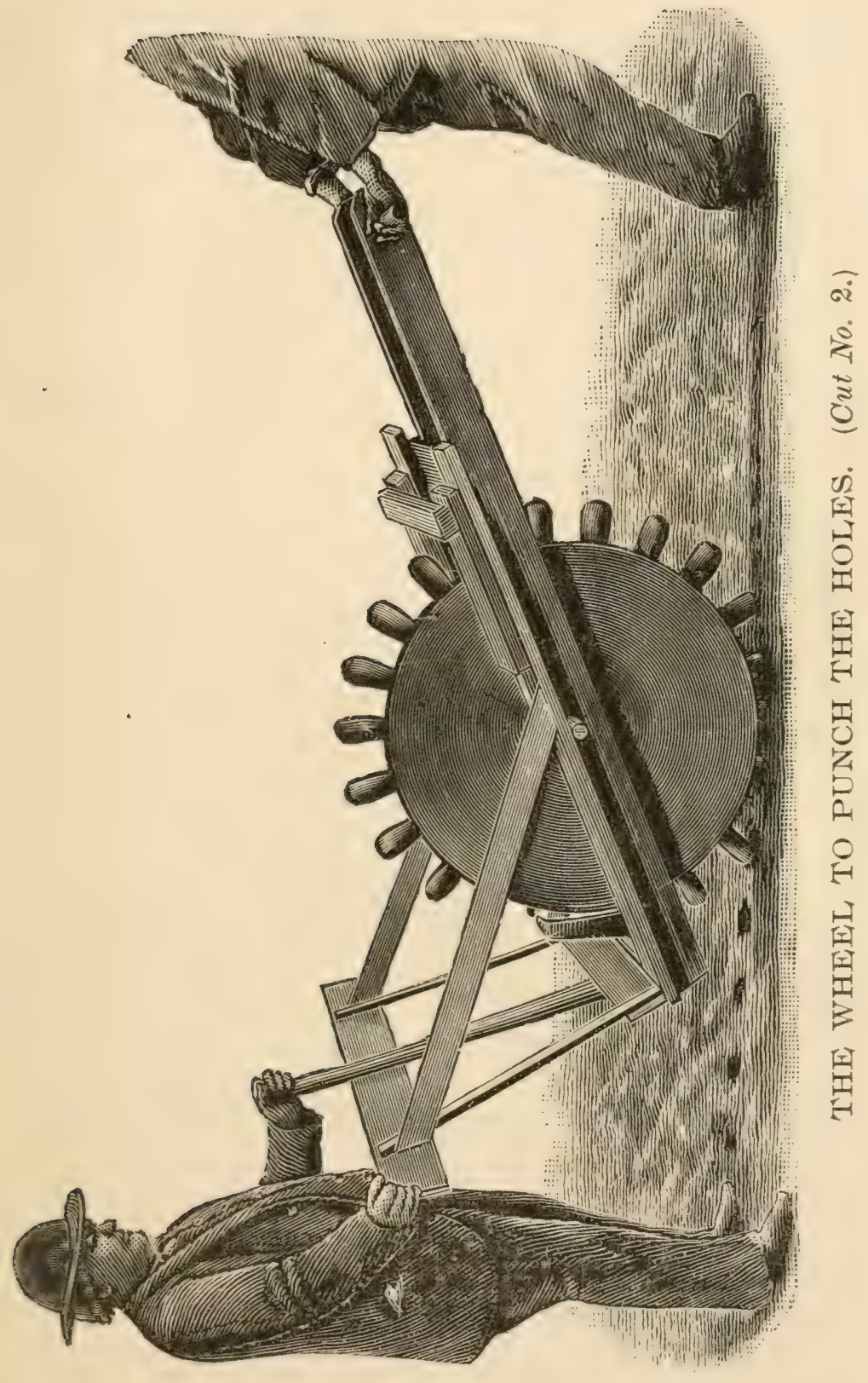



section as far as you can set two rows of each section in May. After the last day of May then set one row and skip two, and so on through the field. In eight or ten days after the first row of the first section was put in, go back and set the second row of all the sections through the field. Then in a few days set the third row, closing the fourth and last row soon after. About sixty-fire clays after the first rows are set they will be ready to bianch, and after the boards are put up to blanch them it will be fourteen to eighteen days hefore the celery is ready to gather. During the time the first rows of the sections are being blanched, the second rows will be making growth to equal in size the first rows. Now when the first rows are white (stalk and heart leaves) lay the boards flat on the ground and harvest the rows as much as you want to malket that day, then put the boards up to the next row, and so on each in its turn through the entire field. Be sure and have a driveway along the end of the rows.

THE WHEEL, ITS CONSTRUCTION AND USE.

(See cut No. 2.)

To make a wheel, pin boards or plank together until you can cut out a wheel forty inches in diameter and six inches in thickness. Now put a twoinch hole exactly through the center; drive in a 
tight-fittingoak pin, twenty-four inches long. Now this pin or shatt becomes a part of the wheel, and when in use revolves in the holes bored into the side pieces by which it is drawn, and is the main part of the frame. These pieces are about six feet long and one inch thick, with a pin put through their front ends to draw by. There is an upright handle at the rear of the wheel with a cross-bar attached; that is to steady it by and hold it vertically true when in use. The other works upon the frame are simply stays, except the hole punchers in the rim and two pieces of cross-cut saw blades for cleaners. IIoles are bored into the center of the surface of the rim with a two-inch auger, five inches deep and five inches apart, with a solid oak pin driven in each hole and projecting four inches from the surface. These pins are to punch the holes into which to set the plants. It does its work well.

Soil is liable to stick to the rim and clog between the pins when wet. In order to overeome that use a pair of serapers. Have your blacksmith cut from old cross-cut saw blade two strips, two inches wide by fourteen inches long. Round and smooth one cul a little so it will not cut the wood; also curve them like a sleigh runner, flatwise, just cnough so that by punching two holes in the other end of each strip and screwing them solid to the outsicle of the frame just at rear of whocl, with 
the edges resting within one-fourth inch of the rim of the wheel, the tip ends of the steels will just meet each other between the punching pins. Now as the wheel revolves, the pins pass through between the tips of the steels and each one gets scraped in its turn and the rim also scraped. (See scrapers in cut.)

Two men handle the wheel just as you see in the cut. When ready to commence setting take the first row. The man drawing will walk in the mark which has been made by the marker, while the one at the rear to steady walks a little to one side so as not to disturb the marks. As the wheel turns, each pin punches a hole for a plant; the holes are about five inches apart. A row forty rods long has 1,424 holes. The soil rolls in and partly fills the holes as the wheel passes, but is readily taken out by the setter.

TAKING UP, SEPARATING AND SETTING THE PLANTS.

Run the wheel in as many rows as you have hands for setting, as it is very particular work and must be done well to get good results. It is best to have each hand set a complete row, as you are therelyy enabled to keep the run of the good or bad work each one does by occisionally crossing the rows which are benig set, to test their prospect for living. You can then see who is setting 
cach row and be able to give instruction according to the needs of each case. The tap root must not be curled up. The earth must be pressed fumly around the plant:

In the mean time the plants are to be gathered and made ready for setting. Take them up with a common spade, kept sharp) as a knife by the use of a flat file. Take a pail of sheep-shears, cut the tops of the plants off two inches above the ground, then the laves camnot eraporate the moisture from the root before it commences to draw support from the earth through its new rootlets, which will show in forty-eight hours after setting in favorable weather. Common milk-pans are good to sort the plants into for carrying to the field.

Ererything being now ready to commence gather. ing, slide the spade full length of blade right under the plants, cutting the tip root $1 \frac{3}{4}$ inches below the surface of the ground, sliding each spadefull off upon a vacant spot of ground where those who gather into pans will have room to work. Each separator needs two pans, one for the large plants and one for the small, so when set in the row each grade will be by itself and the large cannot overshadow the small and so keep them from growing. Or you cain set the small ones close in a bed and transplant to the field after they get larger; for hothouse plants it is a good way to do. 


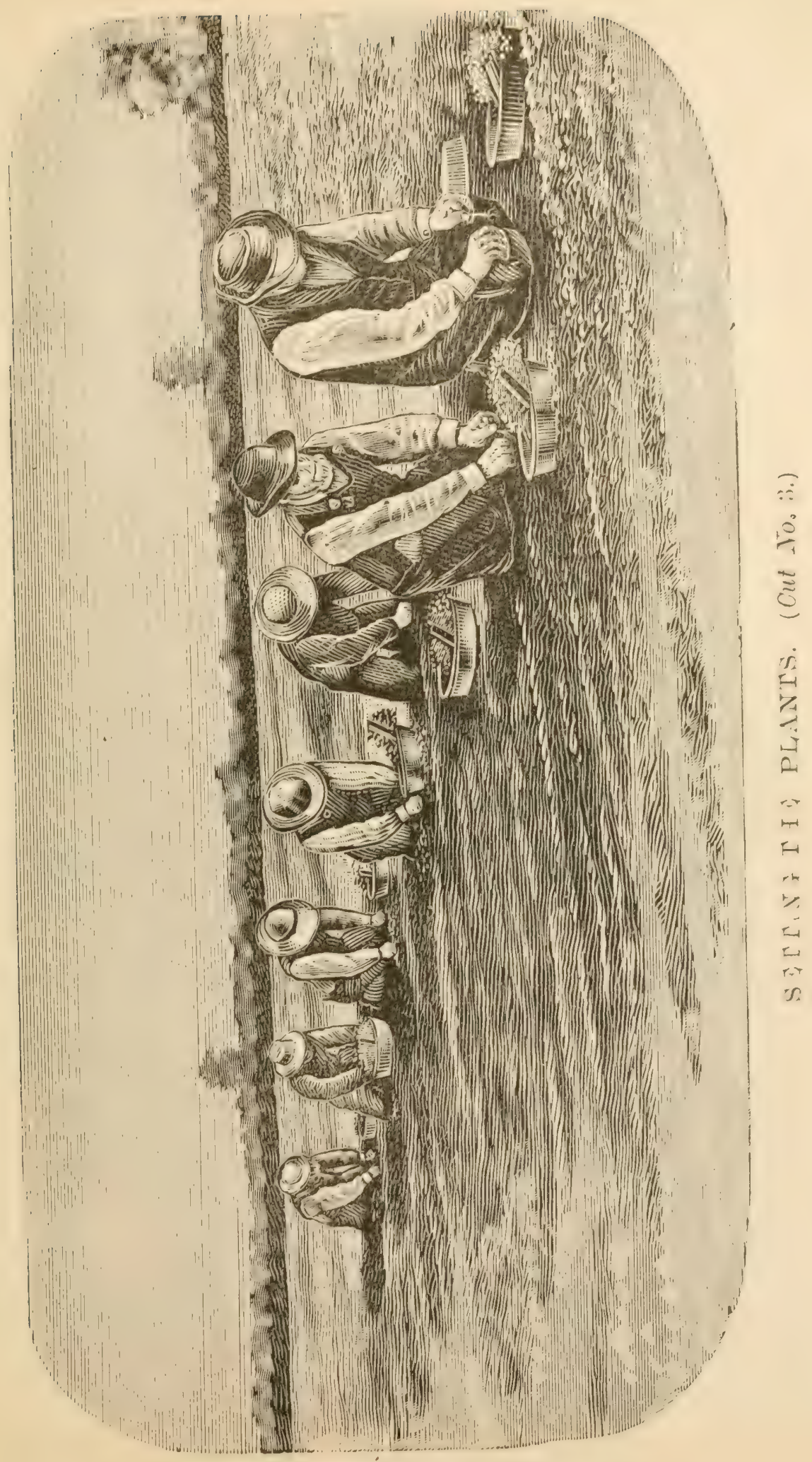



When putting the plants into the pans separate each plant one from the other. Put no grass or weeds in ; have the plants stand nearly upright in the pans, and press close together to keep the air from the roots. Stand the pan while filling it at a slant, so the plants will lean a little, then when the pan is filled put in a handful of earth where the last plant was put, so as to mark the spot for the setter to commence taking out. You will find they come out nicer that way. Then sprinkle each pan of plants with a little water to keep them fresh, and cover with canvas. The pans can be taken to the field on a wheelbarrow. Lay thin boards crosswise, sẹt on one tier of pans, lay boards on top of pans, then another tier of pans, and so on until you have a load. Distribute a few pans every eight rods through the strip that is being set with plants so they will be handy for the setters. Cover each lot with canvas. It is better to have one set of hands to set the plants, another to separate. The latter women or girls can do, and they make the best kind of help.

Setting is easy work as you get accustomed to it. Get upon your knees with a pan of plants opposite, just across the row and within easy reach (see plate No. 3). Take out the last plant put in the pan, grasping it between the thumb and index finger of the left hand, one-quarter inch above the 
crown. With the rient hand take out the soil that hals fiallen into the hole marde by the wheel, then place the root into the hole against the left siele, letting the hand holding the plant rest upon the ground, keeping hold of the plant as advised until you hare filled and packed the carth well around the root with the right, that being your guide to haring the plant set just the right depth in the ground, which is one-quarter inch deeper than it grew in the bed, thus keeping the air away from the roots. Plants set with arre as advised will nearly every one live, eren in hot weather. It is much better to take extra care and time is setting than to set loosely and depend upon their living by watering them.

My hands average five thousand plants per day when the soil is in a gool moist state. The drier the soil the slower the work, as more time is required to firm it around the root. Each setter must have a dibble - a sort of a spud - to make holes for the plants in case of hard places in the field.

In setting plants upon mellow ground the packing of the earth about the roots always settles the plint at least two inches below the level of the land. In case of hard rain-storms it will wash in and cover the plants, hence the earth must be scraped back from both sides of the row. There 


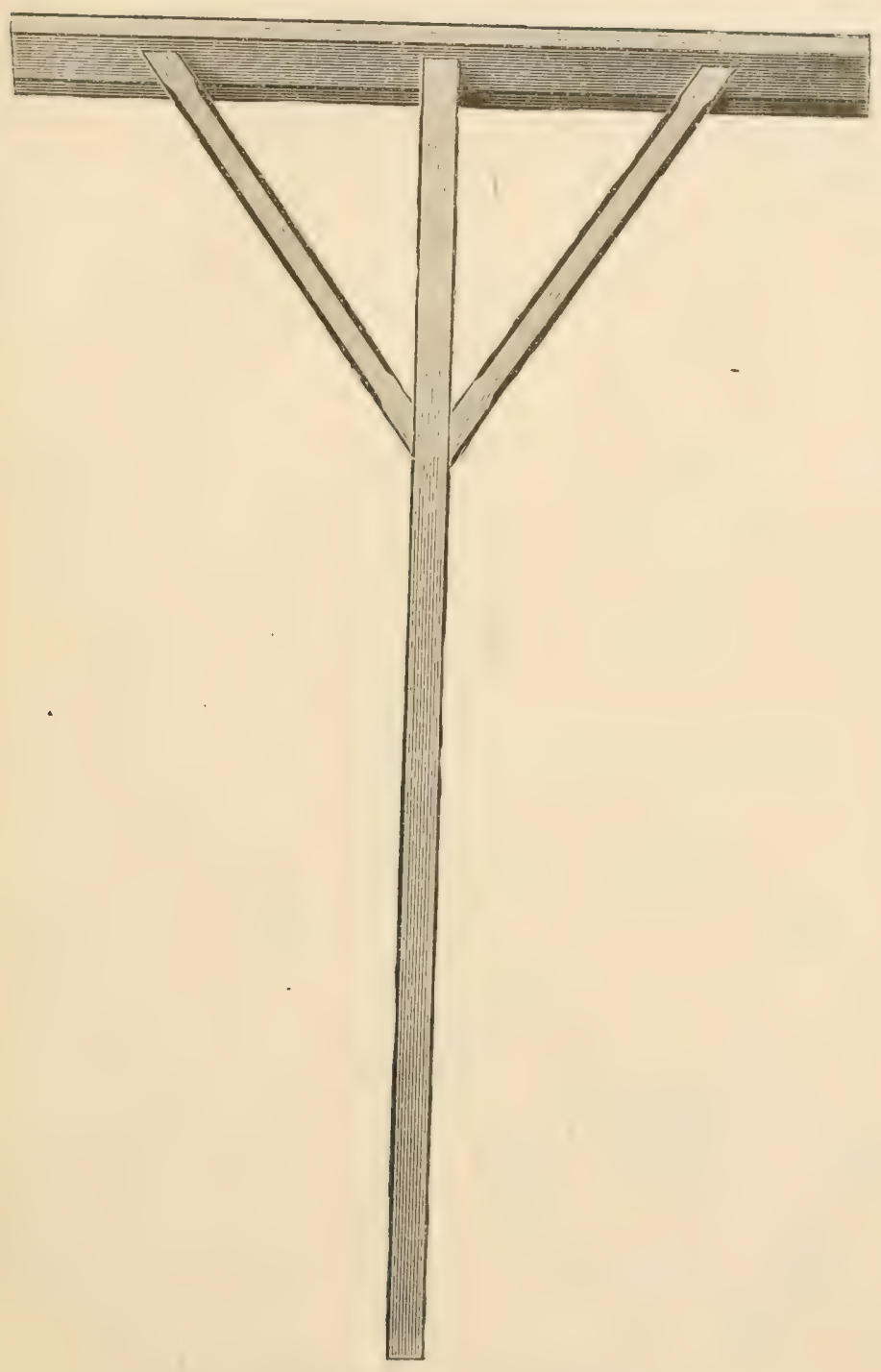

THE SCRAPER. (Cut No. 4) 

is no tool just right for that work, but you can make one by taking a piece of board twenty-four inches long by four wide, and one-half inch thick, chamfer one edge and screw a strip of hoop-iron in front of the chamfer, then attach a handle six feet long and you liave a good tool for scraping back the earth. (See cut No.4.) This we will call the scraper.

Then again, when setting in furrows for earth banking, there is more earth to scrape back, as the celery is several inches below the surface.

CARING FOR OPEN-AIR SEED-BEDS.

Keep the seed-beds free from weeds, and thin out the plants where they are too thick. It is well to be prepared to water the beds, as sometimes the April or May droughts are very severe. There is a critical time in a plant's life, and it must have moisture just as it is coming up. By having inchpipe laid through your seed-beds to connect with windmill, by the use of hose and a rose nozzle you can water the beds. In weeding or thinning out carry off all waste so as not to obstruct the growth of plants. After mowing rake off the tops.

Always be sure and sow enough so as to set nothing but plants of the best order. Some are weak and will never make a good head, others have no heart; such should invariably be thrown away. 
There will always be some plants in a bed much larger thin the general rmn. Those will come in fine play to prick out one at a time through the hed, with some soil at the roots, and set in where the hotbed plants have died out of the rows, in case there are any such. If not, they can be used to set whole rows in order to keep the work moving along-that is, where the hotbed plants have all been set and the others are not large enough to spade.

CARE OF CELERY AFTER SETTING.

After having set the plants the ground must be kept free from weeds. Don't let them get any more than a start. The Planet Junior Cultivator is a good tool for that purpose, also to keep the soil loosened up; yet you cannot take the weeds out of the row with it.

Have your blacksmith make a tool this way: Use a thin piece of steel fourteen inches long by three wide, with one edge kept sharp hy use of file. Have handle like that of garden-rake fastened within one inch of the top of the back of the blade, with braces going near the ends of blade. You will soon become expert in the use of it. By standing a little aheard of your work it will take nearly every weed out of a low from between the plants.

Then once in the seatson, in case the weeds are bald, go over it with a hand weeder, made of a piece 


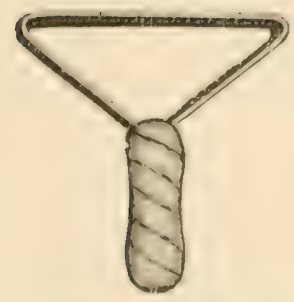

HAND WEEDER. (c'ul No. D.)

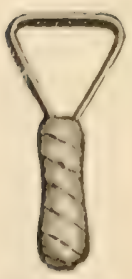

HAND WEEDER. (Cut No.5.) 

of hoop-iron (see cut No.5) fourteen inches long with the ends brought together for a handle, and four inches of the center in a blade, kept sharp to scrape the weeds out from between the plants when they get about five inchęs high.

After plants grow of much size they make it so shady the weeds cannot grow, so that by cultivating you will be able to keep the land perfectly free from weeds and mellow as an ash bed. Weeds like purslane and pigweed should never be left to go to seed upon the ground. In case they escape attention in the forepart of the season and get ad. vanced enough to mature seed when pulled up, gather in baskets and carry off. My grounds, which have grown eight crops, are not much weedy yet, by exercising the precaution given. Yet the land has been very heavily manured. The weeds of course start, but are not allowed to go to seed.

Some plants (by an inherent right, I guess) grow with more vigor than others even after exercising the care in setting as heretofore noted, and as a result of such growth, if not checked, a great many plants per acre fail to make even heads. Therefore, when they get five inches high, take a common hoe, make sharp with a file (and keep so), and go over the field, holding the handle vertical at your side, and with a swinging motion of the hoe head the large plants all back. While they are 
rallying for a new start the small ones are coming gight along, so afterwatels the size will not differ much. I have prateticed it for four years, and alerive great benefit from it.

After the colery gets eight inches high, the ground becomes woll tilled with ronts; then if you continue to altivate do it very lighty, so as to break as fow poots als possible, as it has a tendency to eheck its growth if the groumel is worked deep between the rows.

Now the rows have all been set, hut there may be some plants missing that have fialed to grow from not having been well put in, or a very poor plint set out thit should have been rejected. Gu wree all the rows. Set in large plants where there is one missing and take out those that look feeble, as they will not make good heads. Plants should all be set by the 10th of July. Celery appreciates warm weather, and does not make rapid growth without it.

MATERIALS USEI AND PREPARATIONS FOL BLANCHING.

Tile-blanched relery is very finc, lut it is not practicalbleon a linge scale. It is only done by slow work and is too expensive. But with a few hundred hearls for the garden it is fine. Take two pieces of tin or sheet-iron fifteen inches long, shaped like a half-tile salwed in two lengthwise. Put the two 
pieces together with three hinges so they will readily open and fold. This we call a "folder." Open it, place the concave part against the plant with one end of the folder near the ground, press the plant into the concave of the folder with one hand and graulually close the folder around the plant with the other, letting the elges slip past each other a little so that a four-inch drain tile will slip over the folder down to the ground. Now withdraw the folder; the tile is doing its work. Have the tile set along the rows ahead so as to have them handy.

Paper is also too expensive except upon a small scale for private use. Tiake common brown paper twelve inches by twenty-four in size. Have No. 24 wire cut ready, in length fourteen inches. P'ut the folder around the haul of celery the same as for tile. Wrap the paper around the folder the narrow way twice. It must have two thicknesses to keep out the light. Wrap one wire around two inches helow the top. Draw out the folder, letting the bottom of the paper rest upon the ground, and so on. The paper cimnot well be used more than once.

So much for tile and paper. Now we come to boards. They will please you, I think. Get good barn boards without black knots, twelve inches wide and sixteen feet long. IIave them surfaced 
on both sides, as that makes them lighter, smonth to handle, and will last longer, as they dry quicker after getting wet. You can try ten-inch boards. I have done so, but upon the whole think the twelveinch are best. Pine, pretty free from sap, is the kind to get. Common lumber warps too badly. This lumber can be drawn at your leisure, and onefourth piled along the ends of the rows upon each side of the tichl, and the balance piled where it will be hamdy to draw to the center roid when you get ready to use it, in casse you have a center road, but if not, draw it all to the ends, always piling so it will keep dry.

MAKING THE HOOKS.

After the first rows have been set sixty-fire days, if they have made a firir growth they will stand fiftern inches in height. Now is the time to commence blanching them. A fiw things must be done yet, however. Tho wire hooks to hold the boards up to the celery are to be made. Use a piece of three-inch wagon-tire cighteen inches long, with six holes a little larger than No. 9 wire punched in the edges of one end, and with some lirge holes in the ofher end, through which to spike it fist to a solid block; or an iron vise can be used to good advantige. 'Tilke unamnealed No. 9 wire; with heary wire couters, cut the pienes for the hooks 


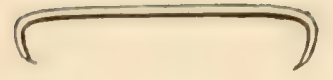

HOOKS FOR BOARDS. (Cut No. 6)

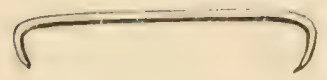

HOOKS FOR BOARDS. (Cut No.6) 

eight inches long and at a slint, so the end of each point will he sharp cnough to stick in the board and hold just as put. Now, to complete the hook, stick one end of the wire into a hole of the bar about one inch and bend it a little more than at a right angle, so the sharp point will stick into the board. Now do the other end the same. It requires as many hooks as boards. Lay the hooks in pans as they are completed, ready for use. (Sec cut No. 6.)

\section{GETTING THE BOARDS ALONG THE ROWS.}

Now we are ready to liny the boards alongside the rows, which is done by the men carrying two boards at a time upon their shoulders, laying both down by the sille of the row to be blanched, then taking the top one and laying it over upon the opposite sicle of same row. Carry one-half way through from the enils to the center road, then load upon a broad-tire wagon and distribute the other half way by drawing through center road. You can have a light cart with wheels six feet apart drawn by a horse, or men. With that spread to the whecls, they will each track just half way between the rows at three feet apart. I lo not think this is as good a way as carrying upon the shoulder; because with the cart you will spoil some celery, the other way none. Make the men handle boards carefully so as not to split, and they are goon for years. 
PUTTING THE BOARDS IN POSITION FOR BLANCHING,

Now we have the boards delivered. Raise the outer edge of the boards and shove them under the celery leaves and press against the heads of celery, then raise $u$, the outer edges, bringing boards to a perpendicular. Now step astride of the boards, hold them in position with the legs, bring in a little earth with the fect, to hold the bottom from springing. out as you press the tops together. Hare the pan of hooks within reach, take out two, slip one orer the boards about three feet from each end. The boards should be about four inches apart in case the celery is good size; if not, a little closer, which can be done by turning the wire hooks a little crosswise on the boards. Now put up another set the same way, having the ends fitting square against the first ones, and so on.

Always commence at center road to work, so if boards do not come out even it will occur at the opposite end of rows. You will probably need some shorter oncs at the enils, as the regular length does not of course always come out just even. Hence saw to fit.

It needs a little earth drawn up to the bottom of the boards with the scraper to keep the light from shining under. Bear in mind that the darker the row can be made the more perfect the blanching, and the quicker. The absence of light causes 
celery to turn white. Ileat favors blanching. Cold retards. Hot sun or wind will change the boards a little. Go over them in five days and right them.

Now we have the crop well under way. There are several important matters near at hand thit need our attention, such as gathering, washing, boxing, and marketing. All of these branches need to be in proportion to the amount of celery raised.

VATS FOR WASHING.

For from one to five acres have two washing vats made, three feet long by two wide, and one foot deep. Material should be pine, one and one-half inches thick. They should be located where the water is handy, as it requires plenty of water. You need a small building to bunch and tie it in. If growing only for home use just blanch and gather as nceded until cold weather approaches, then store it away upon the cellar bottom with some earth on the roots, or build a small storehouse out of doors, as per description further on.

PREPARING FOR HARVESTING AND MARKETING A CROP OF EIGHT TO FORTY ACRES. WATER FOR WASHING AND NECESSARY BUILDINGS.

A windmill is a good way and cheap for getting: a good supply of water. Usually, just where the 
lowlands commence to rise into the high, will be found the most abundant supply of water. This is a good location for the buildings necessary for convenience.

In order to wash celery quickly and cheaply it must be done by hydraulic power. Hence arrangements need to be made with that in view. To commence, erect a frame sixteen feet high to sup)port a water tank. The tank, twelve feet high and ten in diameter at the base, will hold about two hundred barrels of water, with a pressure of twentytwo feet when half full, or twenty-eight when full. This gives plenty of force for washing celery. Have all the water pipes under ground out of the way of frost, except the one from the surface of the ground to the tank; in freezing weather, that can be wrapped with some material to keep out the frost.

A building for washing, bunching, tying and boxing must be erected, thirty feetsquare, with a partition through the center, running east and west so as to get the sunshine in the washing and tying room in the south half of building, with boxing and shipping in the north half. Let there be two openings in the partition, three feet square each, through which to pass the colery, after tying, into the boxing room. Have sliding doors to close the openings when needed. Have the center of the openings one-fourth of the length of the partition 


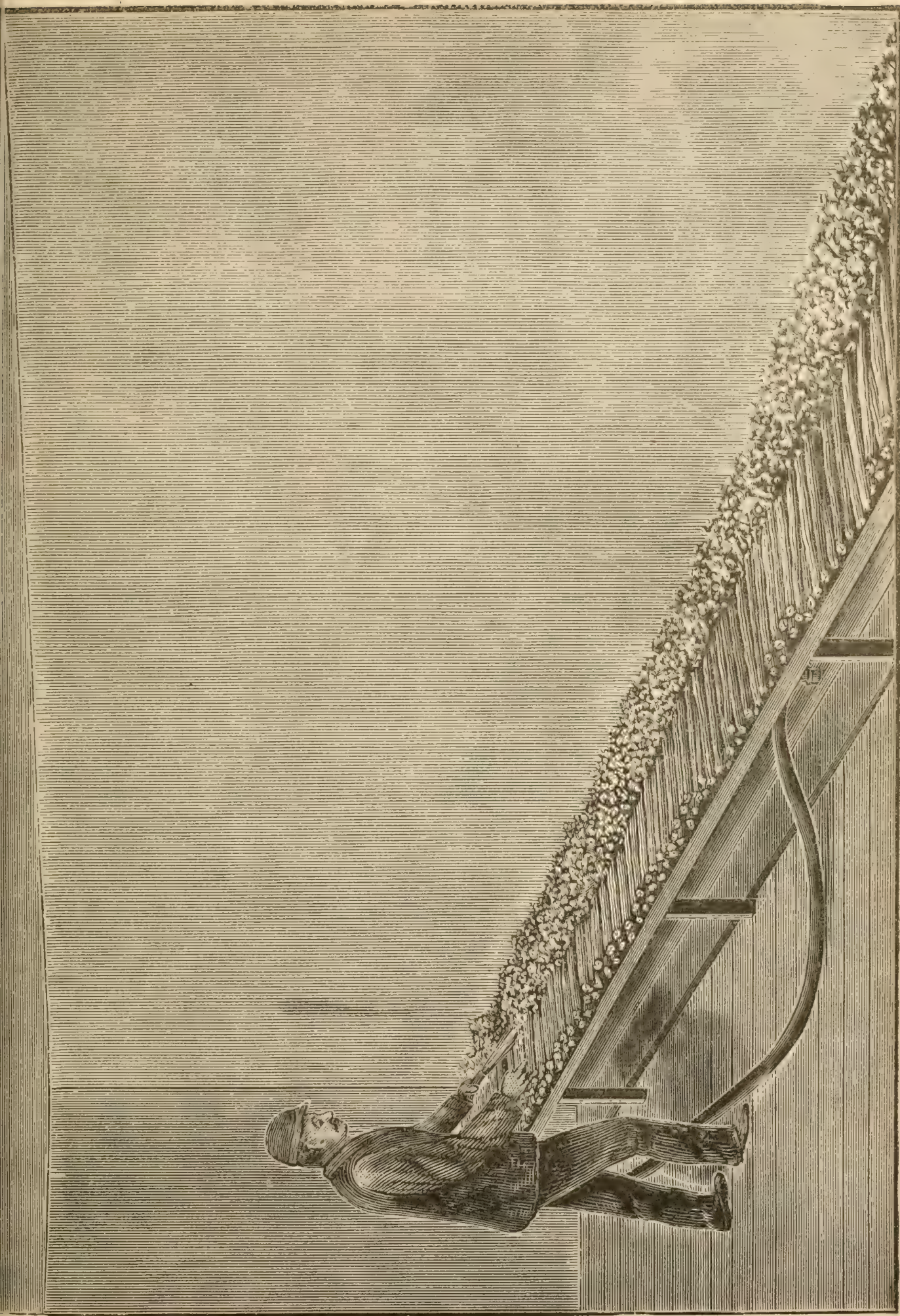



from the ends. The bottom of the opening should be two fect eleven inches abore the floor. Now build a table upon each side of the partition, just the sime height and two feet wide, of perfectly sinooth boards. The one in the boxing room is to let the celery stand on while draining; and the one in the washing part is the tying tilble. See cuts No. 7 and 8, which represent the washing and tying processes.

The washing and tying room needs to be well lighted. It is very fine to have a row of sashes running the whole of the south side so as to get plenty of light for washing, as there is the place to locate the washing rack. Let it occupy the whole length of the south side, unless it should be just room for a door through which to bring in the celery from the field. In case the building stands where the ends are accessible, have one door in each end just half way between the washing rack and the tying table, with both doors swinging outward. The washing rack is to be located against the south wall, two feet wide, twenty-eight inches high at the front edge and twenty-five at the back edge, with no floor under it, but a small ditch to carry off the wash water. The rack is made of strips, one by three inches, placed edgewise and two inches apart. Celery is to be laid upon this while being washed, crosswise of the slats, with the tops from the 
washer. A pipe must enme under ground from the tank pipe mp into t! is rom near the center of the rack, and six inches alove the floor ; to this attar.h. hose with a small nozzle which throws a solid stream. For washing celery, place it wou the ratck about two or three hearls deep. Play the water upon it once over, then turn and repeat, which drives the dirt from it.

This room is to have a stove in it as colll weather comes on, but the parking room hits no stove. Have the pipe to which the hose is attached terminate in a hyllant, with cock attiched to turn water off and on the hose. Lay the floor of this room open, with cracks onc-half inch.

The washing vats before mentioned are very handy in this room occasionally, in case of break in the water works. Jill one vat two-thirds full of celery with tops all one way. Fill with water. Have a limber corn-brush hroom. T'ake your position at the end of the vat where the hutts of the celery are, run the brush over two or three heals at a time, held in one hand just under water, so the motion of the water will aid in cleaning. Have the other vat stand close beside filled with water to rinse in, as it cannot be cleaned thoroughly in one water.

All of these rooms and their paraphernalia should be in fine working order a little alsead of the har- 


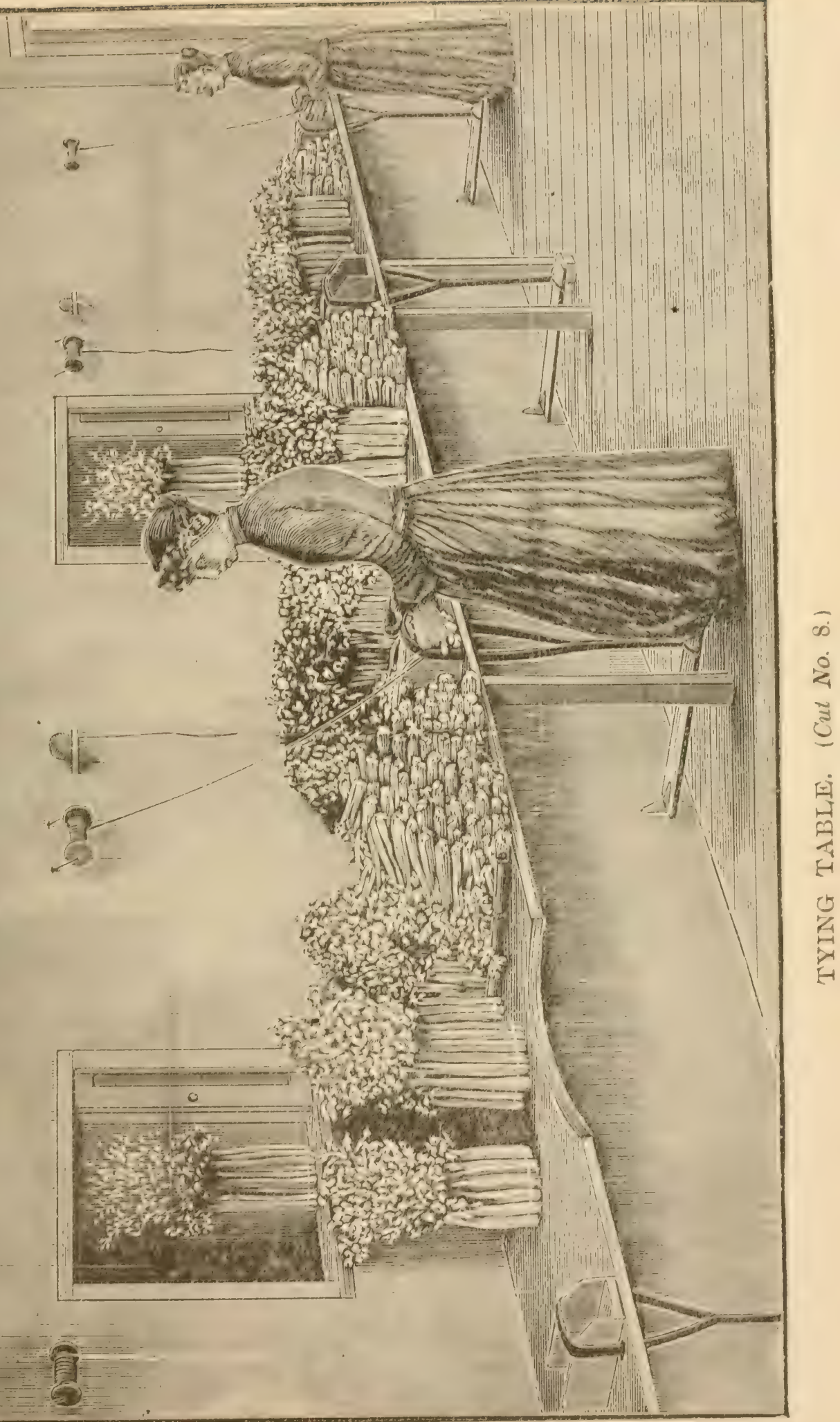



vest, as that is a very busy part of the season, and unless things are in readiness confusion will take possession where order should reigh supreme.

IIOW TO MAKE A BOX IN WHICH TO BUNCH ANI) TTE CELERY.

It is necessilry to tie celcry in some shape for its appearance in market, and I think-there is no better mode than putting twelve heads in a bunch and tying with two coleds or tape. (See cut No.9.) The bunching box is five and onc-hall inches wide, the same in height and ten inclues long. 'The hottom piece is one inch thick. 'The sibles can be of wood, although heary rubber belting is much better, as the celery is not bruised by coming in contact with it as with a hard substance.

\section{ALLOTTING SPACE TO TYERS.}

Eareh tyer must have a box, amb there is remen for four tycrs at this thirty-foot tying table; hence each tyer has seven feet and six inches space, divided ats follows: Mark off four feet and six inches from each end of the tying table. That space is to bay the colery as it enmes to the tyer from the washing rack. Now set a tying hox with the end outwarl, and the buttom contering upon this mirk. Measure from eateh mark six feet firther along, set a tying lox upon cacte mark. This space is fol two tyers to stand their celery after it is tied and talirn 
from the box; it will stand opposite the openings into the farcking or boxing room. The remaining: nine fect of space at the center of the table is for the laying of the celery from the washing rack for the two center tyers.

\section{ADJUSTING FOR THE FOO'T LEVER.}

In tying celery there is too much resistance to bring the cord tight enough with the finger's to hold it. We must have foot leverage. Arrange as follows: Take 12 or 14 oz. Gucking. Makea band two inches wide, having it three thicknesses, stitched along the elges and through the midlle, three feet long. This makes a softand strong band. Now eut an opening throush the tying table, two inches from the edge, a ach sille of the tying box. Put one end of the ducking band down through each hole thus marle, and astride the lox filled with celery. Take a strip of hoard four inches wide, and as long as the tying table is wile; this is for the foot lever. Fisten with a hinge at the back cnd, to the wall, six inches from the floor, having the lever exactly under the tying hox. Put astaple in the lever two inches back from a perpendicular from where the band hangs suspended. Now sew a leather strap) one incls wide between the two ends of the band, slicle a huckle upon the strap, put the end through the stiple, and buckle so as to get the right length 


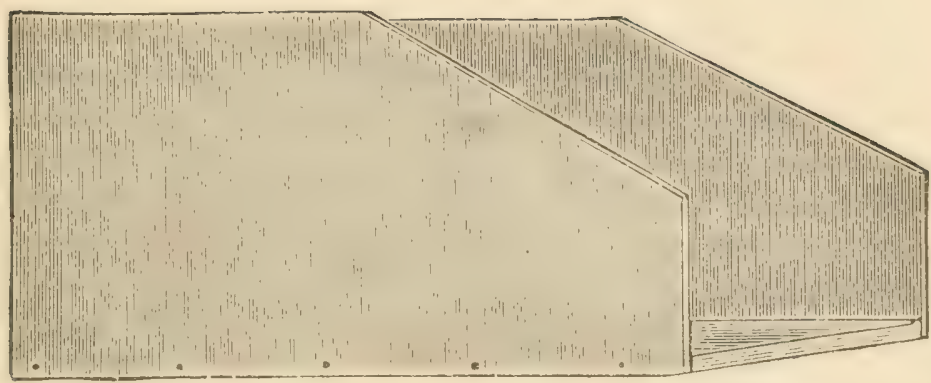

BLNCHING BOX. (f ut li. ?) 

when the foot is mon the end of lever. Cut down the sides of the bex where the band groes over it, so the pressure will all be upon the celery from the top.

It is customary to have two grades of hunches, the first with twelve or thirteen heads, and the second with an indefinite number of small heads, having the bunch a little smaller tham the first grade.

When filling the box let the butts stick over the end an inch, and when rearly to tie miso the hand upover the butts of the celery, letting the pressure come upon the lunch an inch or so back from the ends; put foot upon lever; thus you see the eclery in the box can be pressed smugly together, and held so by the font, while the cond is being ticed around it. The rubber belting for sides of box, with ducking strap, does not bruise it either. Now bringthe cord over the end, tie in a hard knot, draw off the band over the batts; now tie cord without pressure at the tops, but not very tight, as it does not look well for the bunch to see it pincherl in small. Take it out of the box, stand it, upon the table in its allotted place, pinch off all the lraves that give it a shably alpearance, so that it will look symmetrical and neat and show well in the market. When celery is at its best, it is casily bruised in harvesting and washing, and, unless in very careful hands, suffers some by the time it is rearly for the market. 
BEAUTY OF ROPE CRATES.

(See cut No. 10.)

By the use of this appliance celery can be handled in bulk from the field until it lands upon the tying table. It saves all of that handling and pulling apart of a few heads at a time, breaking stalks, tearing off leaves, and the general multilittion of the heads after they once become entangled together. Any one can make them. Always have a goodly lot, as they are cheap and so very handy. I have for my thirty-four acres about sixty.

THEIR CONSTRUCTION OF ROPE.

Each crate has three round pices of wood two feet long, about the size of a broom-handle, one at each end and one through the middle, with a little notch cut in to kecis the rope from slipping whereever it is attached to them. The crate is carried by the sticks at the ends; the center one keeps it spread out all the time. Little tamarack poles when peeledmake good mes. The repes are in size about that of a clothes line; cut them thirty-six inches long, tie knots in the ends; then loop with one linot around the stick, and draw tight. You can pick out all the points of construction by looking sharp at the cut.

Cut No. 11 shows a man hamdling a crate of celery. After being trimmed in the field, it is laid upon the erate, then brought to the wash house in wheel- 


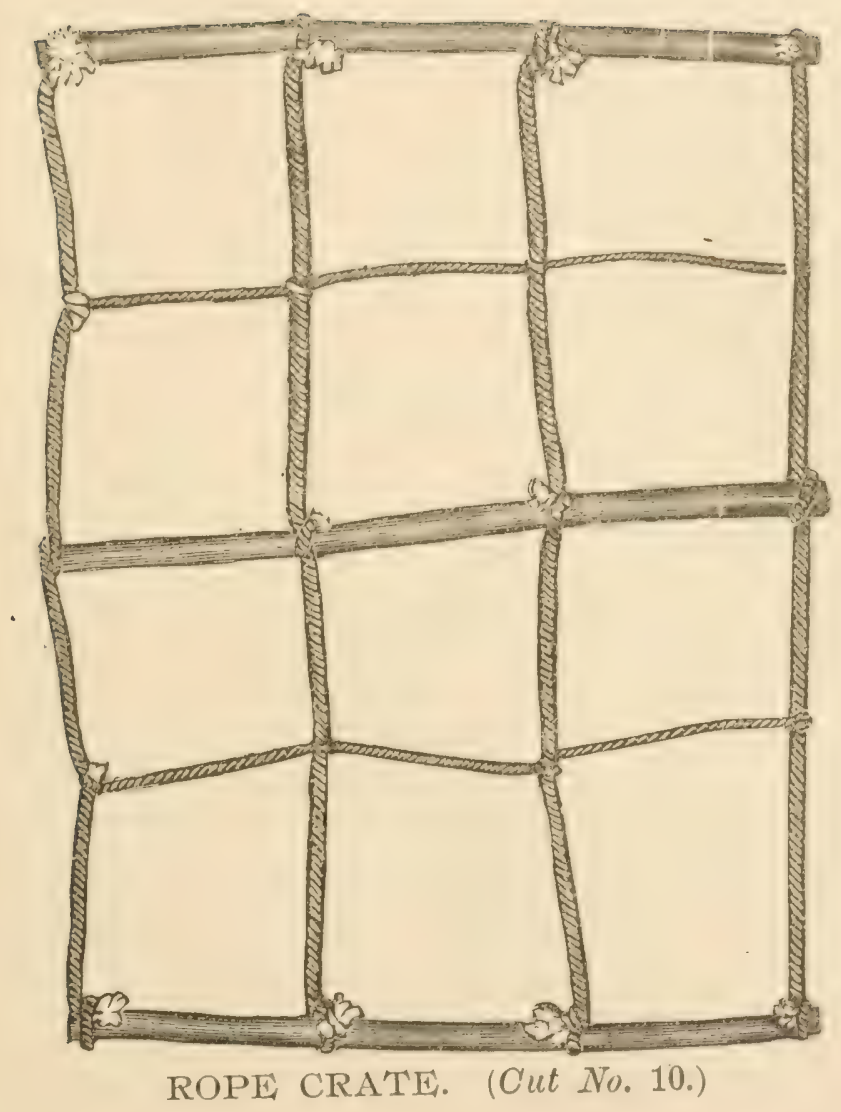



barrow, cart or waggon. The crates can be laid upon each other without harm, until you have a load. For washing lay one ticr of crates upon the rack at a time. Wash while upon the crates, then when washed, lay it upon the tyer's' tables, still in the crates, and they take it from the crates as they bunch it. It can, however, be rolled out of the crate upon the table without much harm if done with care.

There is another way to handle the trimmed celery, that is, in boxes, and it is well to have some of them on hand for extra occasions. Use three-fourths inch pine lumber for bottoms and ends, and one-half inch for sides. Make loxes thirty-six inches long; twelve wide and same in height. Nail strong. Secure the corners by wire staples, as the nails are liable to pull out while in use. Celery can be stood up or laid down. These boxes come in better play when trimming out of the storehouse than in any other place. This same kind of a box is used in carrying the celery into the storehouse when securing the crop for winter.

PASSING TIE IBUNCHES INTO THE PACKING ROOM, ALSO FINISHING ITS CONSTRUCTION.

As the space upon the tying table gets filled, pass it through the opening into the packing or boxing room and stand it upon the table there, which 
we will aill the draining table. As it talkes some time for the water to drain out after it is buncherl, it should alwars be sct upright, and there noweds to be more room than the one drain table already mentioned. Build another just like it against the opposite wall, then hy laying parrer upen the floor underncath, and standing the celery upon that, you find room for as much more.

HAVING THE PACKING ROOM ICED.

By doing oft a space in this room to store a few tons of ice, you will derive a great advantage from it, as celery is quite perishilble in hot weither. By storing it with ice in the winter, and replenishing a.s it melts out in summer, and keeping the openings closed between the two rooms exeept when passing through the celery bunches, it can be kept cold and go into the palcking boxes or calses cold, consequently not suffer from the warm weather.

BUILDING HOUSE FOR BOX LUMBER, TO MAKE THE BOXES IN, ETC.

Close by the packing department needs to be a building, about thirty fect square, to hold the box lumber and make the boxes in, repair return boxes, etc. The building need only be common, to keep out storms, etc. Have all boxas returned when the freight is less than new ones. 


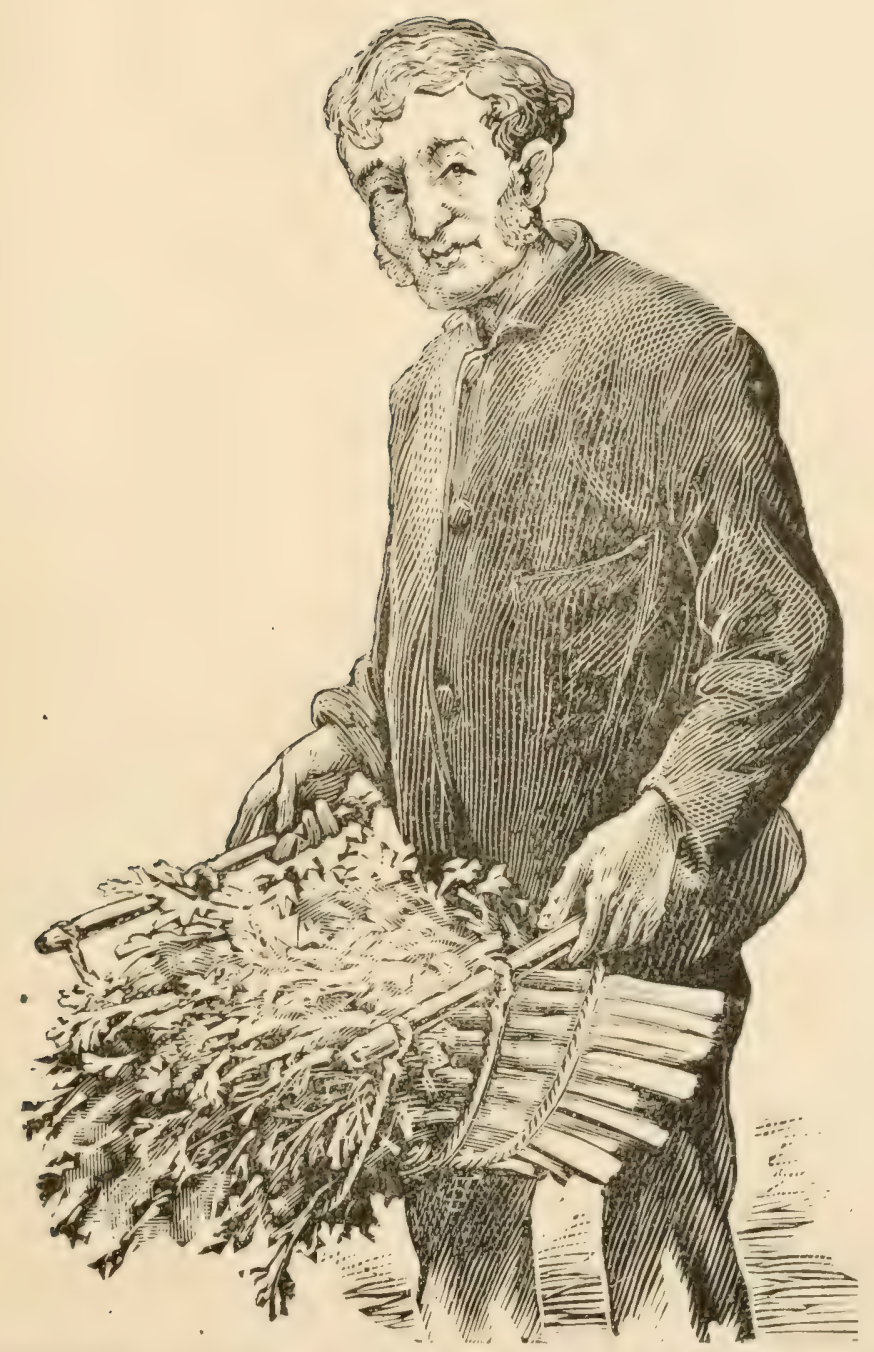

CARRYING CELERY IN ROPE CRATE. (Cut No. 11.) 

SELECTING AND PREPARLAR LUMBER FOR BOXES.

Basswood lumber makes good boxes if it is plump inch. Surface both sides, then resaw; by so doing, one thousand feet makes two. This has plenty of strength for the sides of boxes or cases, but for the rims of cases, have them three-fourths inch thick, and the same for ends. For bottoms of boxes, pine will make good inaterial.

During the warm weather it is best to ship in flat cases, say twenty-six or twenty-eight inches one way by thirty the other, and sevenoreight inches thick, according to size of bunches. Boxes or cases mustal. ways be made to fit the celery, as it must not he loose in the box so as to scrub around. Hence the size will depend upon the season, fertility of land, etc.

For the first year it is best to saw the lumber into lengthis such as you need, after your crop is grown, and you know what is required; but after that you perhaps can tell about what you will need and have it sawed into lengths at the mill. In order to ascertain what size of case is required, lay out the bunches close together, just as it is to be placed into the case, then measure the space it occupies, and make case accordingly.

\section{BOXING CELERY.}

When boxing to ship by cars, always let the tops lap past and upon each other, and the butts always 
to the end of box. Have the tops lap enough to keep even with the butts, and when filled be nosag or looseness in the center of box. Just one single layer of bunches is all that is put into a case, usually ten dozen. As cool weather comes on, ship in boxes that hold from twelve to twenty dozen, but those that hold sixteen are the best. Have the box a few inches longer than the celery, line with thin brown paper so that the sides will not chate; put in with care two rows of bunches abreast. The size I use for No. 1 celery is thirty inches long, twenty-four high, and twelve wide. That is the size for sixteen dozen. Press in so that there will be no chucking around while in transit. When loading into and unloading from the wagon for shipment do it with care. While going to shipping place with load, always cover with canvas to keep cool, especially in warm weather.

\section{PACKING ROOM SHOULD BE FROST PROOF.}

The outside walls of the packing room and its roof must be frost proof. A very grood way to have it so is to make it with two sets of studding, twelve inches apart, filled in with sawdust and lined inside with parchment building paper; for the roof, fill in with forest leaves. These modes are of course cheap and efficient, yet there are other ways of obtaining the same results. 
There is liable to be extensive loss, besides an endless amount of vexation, unless a celery grower is prepared to meet the ching ging elements, arkl the general condition of things as they come along. We can make money by expending money in judicious outlays. If you are in earnest in growing celery, don't be afraid that it will net pay you to take the best of care of it. The crop can be kept until mid winter, or even into May, but everyone must learn for themselves by experience whether it is profitable to keep late or not.

By having the packing room frost proof, there will be two valuable benefits derived: It will be cool in summer, and warm in winter. In case you are still marketing when a real cold time comes along, you are prepared to be safe from a loss. By leaving a little fire in the washing room stove at night to keep the water works from freezing; and having all of the celery put into the packing room, you will be able to keep right along at your business without suffering loss. If you are a little fearful that the frost will get into the packing room on any particularly cold night, leave more fire in the washing room stove, and leave the slide doors open, or pack the celery in the boxes. Have them well lined with paper, as it will take several degrees extra cold to reach it when so secured. In fact boxes should always be lined in winter in shipping. 
any distance, even in mild times, as it is liable to turn very cold within a few hours.

\section{A TOOL HOUSE NEEDED.}

Have the buildings all stand noar together. I find there is one yet lacking to make the set complete, that is, a tool house, from sixteen to twenty feet square, for the celery tools and the paraphernalia required incident to a suceessful business. Around the walls have hooks and nails to hang ul' spaldes, crates, canvals covers, saws, etc. "A place for crerything, and everything in its place," is a good motto to place in full view in this building.

\section{IRRIGATING THE CROP.}

I wish to callattention to this point: Those who find they liare the lind, and are going to follow this branch of horticulture, in case there is any way to mrigate the land should get it in readiness as soon as possible. My own experience in this gives me data from which to advise. The two years of 1888 and 1889 were years of noted droughts here; no rain to wet for several months; caich year I lost twelve acres. My crop was several thousand dollars short of what it would have been had the ground been irrigated. During this time I was studying how it could be done. There was no stream 
of water that could be utilized. The only show was from bencatl. In the mean time I learned that there was gravel under most of these peat beds. There was in my field, just where the high land breaks into the low, a moist place; it was at the head of a drain ditch, which runs one hundred and twenty rods through the center of the whole length of my celery field. I dug down three feet in this moist spot, came to gravel, went two fect farther, when water came in very fast.

I now saw I had a bonanza in water, consequently planned to dig a reservoir at once, and put in some kind of a pump to lift the water out into the ditch. A hole was now dug down, seven feet deep, twenty feet long and ten feet wide. It had to be curbed, as the inflow of water was so great, after getting down five feet, that the bankis would not stand the flow of water undermining them.

I had a fourtcen-foot windmill erected, put in an incline pump of my own make, and irrigated my celery crop in 1890 for the first. After running the pump a few weeks, and still no rains, the inflow of water diminished, and the cry was "more water." So I explored the gravel depth, which was quite coarse, and found it continuous. I then drove down into the bottom of the reservoir, at different levels, from eight to twenty-six fect, twelve pipes with points attached, such as are used for drive wells; in 


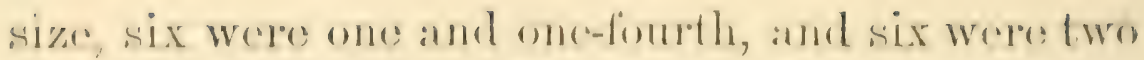
incless in diamefre. 'Tlery were distrihuted over.

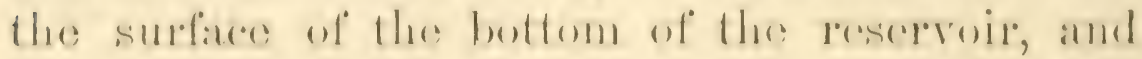
driven so that only six inclese of the top end of the pipe was above the grabel, and ciald one of them threw a full stream withontany dimimution of volunc, of waler which hald enme in at the surface of the bottom. Now there was plenty of watre; did not see the bottom again. I now hecame convinced 1hist the windmill livelsel puwer excopt on very windy dias. It should have beon twenty foet in size instead of fomptecu. As I had no engine (which hy the way is just the thing) I borrowed an oldfashionod horse-power of a neightme, and used that with two horses for the billance of the season with perfecet success.

The pump was fashiomed as follows (I had seen the simme principle demonstrated in draining gold mincs in Cilliformia): 'Tilke two hamelwool boatris, such as will weale smooth, one inch thick allee being surlined, twclve inches wile and fourteen fret long. One of those is for the bothom of the pmmp spout, the othere is fore the top; lay a four-inch hlock

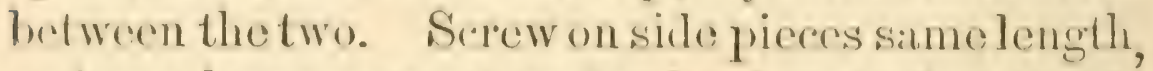
and you have aspout twalva hy four inches inside in the clear. Now screw and brace, just over the opening at ong ent, two mpright pieces, one upun eich sille, to holil a wood boxing in which to run 
an iron shaft of three-inch gats pije, which is to carry a drum made of wool, thirty inches in diameter. Upen the end of this dram, next to the power, serew fist a cog-rim eighteen inches in diameter. 'The gearing shaft comes right up to this cog-wherel, terminating in a pinion wheel about four inches in diancter which communicates power to the drum, and thedrun rovolves an calless rubber belt twelve inches wide, which his wooden pieces two inches thick and a little less than twolve inches long and three and one half inches wille, with one edge chambered, and the other scerowed fitst, crosswise to the belt, every eighteen inches.

Now, to finish, screw solid two pieces at the lower end of spout, one upon cach side, to carry a pulley eight inches in diancter; upon this revolves the rubber belting that holils the buckets, which orce the water out through the spout in a solid stream. Have iron shalt go through the pulley, about one inch in diamoter and run in wooden boxes. This part will always be under water, conserpuently needs no oil. Now slope away the bank at one end of the reservoir, put a bed piece for the upper end to rest upon fifteen inches below thesurface of the land. The lower bed piece can be the curbing cut down enough so that the lower end of the pump spout will be six inches above the bottom of the rescrvoir.

Go slowly when first starting the pump, as it is 
liable to give such motion to the water that the gravel will whirl into the pump and clog it, but as soon as the water ean be lowered enough, shovel out a pit and stake down a floor four or five fect square, under the cond where tho water boils as the buckets come around.

I run the water bark to the far end of the field through the center ditch, then cut an open lateral ditch earch way from it twolve incless wirle and fifteren deep, nearly to the firr sirle of celery fichl, which is forty rods carch way, the main ditch being in the renter of eighty acres. In about half my lateral ditehes I have put six-inch tile, which works to a rharm. This first ditch is six rods from the end of the celery field. Then there is a lateral ditch crery twelve rods upon cach sicle, same as first, cleal batck to heald of ficld. I have water enough to run three ditehess at the same time. The water solis through the ground and meets at center line leetween the two laterals in about four days. I dan those up and set three new ones in motion, and so 611. I have several rises interspersed through my grounds, of gratrolly soil, and too high for celery hreause I camnot wet them. This whole system of irrigation costs hut little, and in a droughty year is worth from two to three humdred dollars per acre, so you see that the cxtra production of one acre will more than pay for it in one crop. During a run of 
wet years no irrigation is rerpuired, but in such droughty ones as 1888, 1889 and 1890 ("verything needs irrigating.

There is another system by which lind can be irrigated from an open or a drive well or any head of water supply, just in proportion to the supply and arpacity of machine. It is Gould's Centrifugal Pump. I presume any home dealer-in that line could inform you about it. It is comparatively a new device, however. There is a man in my town who puts them in, by the name of L. M. Watchon. Tle helped me put mine in that has been describerl. There are some places where irrigating can be done from a spring or creeli upon the premises. Of course those are choice places.

REVHEWTA THE CEIERY HILL AND THE WORKMEN,

We have the repol, now well under way, being nearly rearly to commener raking in the shekels. This gives an impetus to business. Thero neels to be from the vary starting of the husiness a hearl to it, in oreler to inspire a high grate of suceess. If this is not the owner himself, then he should have a well-paid superintemlent-woll-paid in order that we can reasonahly expect his very best efforts. To have caparity, he must be the possessor of order, system, ingenuity, a desire to turn out is superior prorluction, and earn his money. By the way, those fellows are not very plentiful. 
I trust I may be pardomed for giving my experi enre in this dine. Price ler ordinary farm labor here in Mirdigan isonedollate and twenty-live rents porday. Now my plan isthis: Godthebesthamds and pay the best wages-that is, paly rarh ome just what they can carm, man or womall, by exereising prulence, thoughtlulness, diligent attention to husiness, the eximple they set belione the rest of the workmen, and with a willing hamel and heart to help' in every emergeney. My reseapest male help has ance dollate and tilty cents pere diy . If he canmot

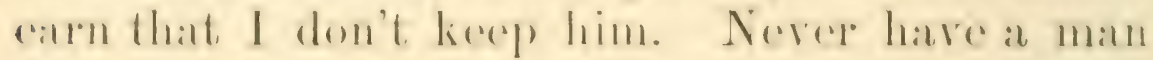
that goes into a saloon, or who associates with the class who do, as the contamination is latal. I pay from the one filty pere day up te six humbed dollats per ycill; most of my dity latwers, however, got two dollars per day. Men hy the month, from twenty fo forty dollars and board. The eonsequence is my help stay right along your after your, andall lay up money.

Ori the arraige I employ twelve hamels. From three to four are women, who live upon the place. They separate the plants, and put them into the pans, while the men set them out. They also ween out the plant beds, and do all the bumching and tying. They are choice help. Of course I do not put them at any of the harel work. Those I employ hatre been with me four years. At fifty ants per 
hundred for bunching and tying edery some of them carn two dollars pere dity. They ares neater and more painstaking with their work, usually, than men; (onssequently their help) is worth more, rather thitn less, flian men's. I have three good houses upon the place, orempicel by families. I also have help, both male and fimale, that have worked for mo four years without giving me an unkind or saucy word, and thry have not been balhed either. Every one must attemel strictly to business in husiness hours. They are not of the low, lesotted whisky grade. Help which do mot save their carmings are usually of the very poorest order.

There is 110 : ime, after the celory has been set, in the firld unt il the last head has been gathered, that the superintendent should not give all parts of the field a personal inspection every other day, so that in case anything is going wrong it can be righted before getting ton far gone. When plants are first. set, the earth is to he sceraped back; if not woll done, and a heavy washing rain-storm comes on, plants are liable to be covered at the heart with soil and spoiled.

There is a yellow worm, known as the wire-worm, which is an encmy to the young plant, as it bores into its tap root just below the crown, and kills it. The remedy is, set in the largest plants you have, and twice as many as needed; after danger is past, 
thin to right distance. Also kill all worms found. It is only occasionally they do damage, and then in patches.

The common brown corn cut-worm is occasionally mischievous, but does very little serious harm; as the heart of the plant is not injured, it grows right ilong. If cut off too many times, however, its growth is so retarded that a new plant is needed in its place.

See also that the weeds are not getting a start. Have the places of all dead or puny plants filled with strong ones. Keep the skirtings of the celery ficld mown down, as grasshoppers breel upon the grass, and eat the celery leaves if allowed to hatch out.

If sheep are pastured in an adjourning field, see to it that the fences are perfect, as they would be very destructive in case they broke in at night.

Look for purslane; if any has escaped and is now in bloom it will mature its seed if pulled and left upon the ground. Carry it all off. Do the same with all bad weeds if left until going to seed.

See to it that the blanching boards keep their position. There mist be no openings under for the light to shine in, thereby retarding the whitening. of the celery. In case the lower edge of the board is warping out, put it back and bring up earth enough with the foot and tread down to hold it. 
See to it that you have an acre or so, near the washing house, that is early enough to be harvested out of the way by first of October. You want this site to build the storehouses upon, in which the balance of the crop is stored upon the approach of cold weather.

Plan to have all storehouses near by headquarters. Otherwise, in cold weather celery might freeze in bringing to wash room unless carefully protected.

In the cultivating process with the horse, be sure and select a careful hand, one that will be sorry to see a head of celery mutilated. 'Turn the horse at the end of row so as not to tread it down. There are always destructive agents enough at work without hiring it done.

Have the tools of the best order, and see to it that they are in proper condition to do good work. Be upon the ground the first in the morning; with plans all matured for the day. See as each hand arrives that they take hold of their work understandingly. You can well afford to give close attention to the business during the growing season, as there are several months each year when you are comparatively free. I have always superintended my own celery growing from the fact that I never have been able to hire a man that was quite as much interested in my success as I am myself. 
A tract of good land treated as here advised will pay a clear net profit of throce to six liundred dollars per acre. This is clear of all expense of producing and marketing. I have had choice acres which have netted me twelve hundred dollars per acre, but that is as nothing; we must look at the average of the whole tract for a suceession of years.

For the year 1890 I had thirty-four acres in celery. By comnt there were thirteen hundred thousand plants upon the thirty-four acres of ground. A good shame of the rows were three feet apart; all that were earth banked were four feet. I also had several acres set to doulle rows, that is, two rows nine inches apart, with three feet hetween, but shall raise no more that way, as the heads do not grow quite large enough to satisfy the market. There are about forty thousand per acre when set to double rows in such distance as named.

COMMENCING THE HARVEST.

We need two wheelbarrows, with enough thin boards four fect long to corer the bottom crosswise, upon which to licy the erates of celery to be transferred to the wash-house. IT e must have the sharp spaude and a few pans to put the hooks in as taken from the boards, also an old-fashioned case knife for each hand to trim with, about eight crates for each wheelbarrow load of celery, and canvas to cover with, especially in sunshiny weather. 
Take off hooks, put into a pan, open the boards and let lay flat upon the ground. When the celery is ripe, in case of White Plume the heart stalks are white, also the leaves; but of other kinds the stalks are white or yellow, but the leaves remain green.

Now if the celery is ripe upon examination, slide the spade under a root or two at a time, cutting a little below the surface; have a hand or two follow up, and trim off the root, also the outside stalks, leaving the edible part only. For example, take head in one hand, setknife in a little above where the outside stalk is attached to the root, cut at a slant all around, leaving the butt in cone shape, strip off all the stalks that are not blanched (the outside ones never blanch and are to be stripped off), cutting from where the last stalk breaks from the head, leaving trimmed part smooth.

There is another way, that is, to cut the root square off at first, one-inch below the last stalk, then break off the unblanched stalks, trim all the rough off so as to leave smooth but still cone shape.

There is still another way; cut it square off atflrst close to the head, then break off unblanched leaves, then cut again so as to leave no root at all to the head. In this last way of trimming, some heads are spoiled, as you are liable to cut too far up and 
all the stalks fill off separate. Hence it is not as good as the cone shaped ways.

Now, when trimmed, place upon the blanching board in little piles within reach as you work your way along, then in turn gather these into the crates, laying the crates upon the refuse leaves and stalks. Keep them covered with canvas, as celery wilts very readily in sun or wind; consequently, let no small piles lay more than eight or ten minutes. At first a few dozen will be enough to harvest, say one row, thirty or forty rods in length.

Now, after it is trimmed out, put the boards right up on the next now, just the same as they were on the first, spread the wash rack with crates singly, wash as directed lay crates upon tying table, and with the tying box in position, put in twelve heads, three aljreast and four high. In case there is a small one in the bunch, so it is not quite even, fill out with another small one. Now put the band over for giving pressure, put foot upon lever, bring the heads snug together. Always have the butts come out of the box one inch so the tying cord will wrap around, tie in hard knot, har re a sharp knife lying upon the table to cut the cord. Have the ball in a little box opposite tacked to the wall three fect above the table. Unwind it from the center as used. There is a narrow white and purple tape that is nice to tie with in case you 
send to a fancy market. It comes upon spools of one thousand yards each, and costs two dollars and twenty-five cents (three times as much as cord).

\section{MARKETING THE CROP.}

In sending out your first shipments, it is well to make some small cases that will hold four or six dozen each; but for home markets, where you deliver with your own conveyance, lay loose in boxes. Supply home markets liberaily. You will besurprised at the amount they will use if your celery is nice.

It is best to send some away by express at first gathering, so as to see how it stands in the markets abroad. Line your cases with wrapping paper so as to keep the colery from getting marred. In packing; set the case upon the floor at a slant, leaning against some support, put in the paper lining. When the case is made one side is not nailed on, but the boards are fitted and laid in the case for the corer. After the case is packed (and the celery should be crowded in tight) set it upon a box made for that purpose about one foot high, lay a lining paper over the celery, nail on the cover, then stand it on the edge as when it was packed. Have a rubber stencil with your address, and stamp 
upon the upper rim, as it wants to ride that way u1). Have empty cases returned to you. Now put all the small heads of celery into bunches by themselves for second grade.

Stamp each case or box first or second grarle, just as it is. Right from the start, deal square with the trade. If there is an imperfect head and it is put into the bunch, have it put upon the outside so as to be seen. Yet the best way is to never jut in a hearl that is defective, especially one that is rusting or rotting. There are so many people nowadays that do just as they do not want to have others do to then, that when a buyer finds a producer who puts up his products honestly, so that lie can, with a feeling of assurance, guarantee to his patrons that the goods under a certain brand are just as good all the way through as they show up)on the surface, it will be away in the dim future that such a producer will ever think of the need of looking for a new market.

Marketing is a study by itself. The eye is to be pleased. That sense is in the advance. The attractiveness of an article frequently makes its own sille, even when not possessing within itself any real merit over its less pretentious neighbor. Such is the case with the white-leaved celery. Thereare several kinds fir ahcal of it in elibility, but unfintunately do not possess that heautiful attractive 
appearance of the White Plume, which is such a fine decorator of the table.

It pays well for every one engaged in the celery business to establish a reputation of their own in the markets which they intend to use. You can well afford to make a special effort to work up a remunerative market, in case your product will warrant the expense.

The best way to find out what others are doing in the celery business, is to take a bunch of your celery of an average grade, tie a bunch of damp peat moss upon the butts, then wrap all in paper to protect from the air and getting marred, and take the early train for your nearest city; inquire for the fancy grocer of the town, and show up to him just what you have, also what you can do in supplying him with such goods, and at what price free on board the cars at your place - that is, the purchaser paying the expressage or freight. It is well to show your goods to a half dozen dealers while in town. Carry this inquiry along at least until you are satistied that you have found your markets. It will do you but very little if any good to make this trip without a sample of colery.

Don't neglect to look up the financial standing of your patrons. Whereyou visit a town as advised, you can do it while there. In case you propose to send away to strangers, look up their standing from 
one of the commercial reports, such as Bradstreet or Dun. They now have agencies in all cities of any size. It will pay you to buy one of their July books, if you have a few acres and don't want to sell it all at your home market.

In case you have fine goods, there is very little danger of your losing anything through your patrons not paying, even in case they are slow. If you furnish them with a choice grade of groods, they will sell them out readily, consequently be able to pay, and so not be fixed to find any good excuse; still wanting you to keep on furnishing them, you are pretty sure of the pay promptly. There are what are considered poor or uncertain payers, and would be, on a poor article.

Be sure and have it throughiy understood that you will expect a remittince upon each Monday of pary in full for the celery of the past week. Have it so written upon your letter-heads, then they cannot overlook it or forget it.

One-tenth of one per cent. is all I lost in seven years in the business, selling to two or three hundred buyers and in twenty-two different States. You see that is only one dollar on a thousand.

Don't make a practice of sending all your crop to a commission house, as some of them are unreliable, having no capital and changing from place to plice, and have no standing in the commercial re- 
ports. Yet some of them are No. 1, will get good prices and are prompt pay. You will find such reported as to their probable capital and grade of pay. But you have to pay them ten per cent. for selling, which if done by yourself is so much saved, and in case you have fine goods you can get just as much or more than they.

There are times and places, however, when and where they come in just right. For example, you lave some choice celery and want to extend your trade. Now go to the express agent of your town, ask him to send to the company and get a list of the names of dealers in such goods as fruits and horticultural products. They have them on hand ready for distribution, getting their reward by your patronage. You may not be able to tell whether they are commission men or grocers; but after getting names of dealers and places, write them stating what you have, asking them to reply and let you know what the prospects are with them for selling celery, and at about what price. Ask if they are commission men or grocers. You can always ship to commission houses without notice whenever you can get their names. They will sell and report, usually remitting proceeds at same time, but with grocers it is far different. They usually will not receive the goods unless upon their order, from the fact that a great deal is sent them such as they 
can easily get and are alreadysupplied witl. Yours may be ever so nice, such as had never been seen in that market; yet the groeer does not know it, as it is boxed, hence cannot be seen.

I have had some such experience myself at rarious times. A few years ago I sent a ten-dozen case to a grocer in Ohio. He would not receive i: Told the expressman there that he hat orilerenl none from me. This was in the early days of my growing it, and before this high fancy grade with all the new appliances was produced by any one else, consequently could only be gotten from my grounds. So the expressman telegraphed to my home expressman the condition of things, asking what to do with the celery. I telegraphed him to sell it to some other grocer for sample. The outcome of it was that a grocer just across the street got it, and when opened up for sile it was a surprise. No one had ever seen any thing like it in the town, and it created a celery excitement. There was not enough to go around, so he sent for more and I supplied him, greatly to the sorrow of the groecr who had rejected the first case. He was more surprised than any one else to know that he had let such a chance slip through his hands unwittingly. He sent an order at once and continued to occasionally for three years, but I could never send him any, as I only supply one house in a town at a time. 
I soon learned how to avoid such difficulties, and it is a good way to do. Have your home expressman whom you patronize write the agent at the town where you propose to ship, requesting him to vouch for the excellence of the celery to the consignee, with the understanding to open the box and in. case he is not pleased reject it, but so far there has not been a rejection.

One more sample of this will suffice. I showed sample to a grocery house in Cleveland, Ohio, in the year 1886 , started on an order of forty dozen per day, and in eight days their order increased to four hundred dozen. Of course then I had to call a halt.

Hence it settles right down to this: If you produce a fancy grade of celery, send it into any town in the whole country, to commission man or grocer, and you will hear from it quickly, also have an order for more in nearly every case. If it is a com. mission man, every grocer in town will see it, and they will find out in some way where it came from, and they will order from you. Then look up their financial standing in the commercial agency report, and take your choice as to whom you will supply, and if your celery is fine you will be able to set your own price. Hence I think it is apparent that all of the minor details, as well as the great, need the best thought and attention of the one in charge. 
Celery, after it is ripe, is not liable to remain in a perfect state more than four or five days during the hot weather of July and August. One of the first appearinees of deterioration is a whitish limesprinkled appearance upon the outer stalks next the ground. This is apt to show distinctly in case of hot and wet weather. The stalks at that point will soon get solt or pithy, consequently keep gathered as fast as ripe. The White Plume variety deteriorates much sooner from over-ripeness than most other varieties.

It is to be particularly noted that it is against your best interests to send any of the second grade celery into your best markets, excepting you are sending large quantities in car lots. Expressage is expensive, rates are too high, and we cannot feel reconciled to give them all of our business, and are all the time looking for some way out to a cheaper scale. For example, in the large cities there are wholesale dealers who buy in car lots and sell it out to the grocers, hotels and large restaurants, and whenever a grower finds an opening of that kind, he is well fixed. They usually want both first and second grades, and that is good for the grower. If you have a large acreage, such orders can be filled more readily, especially when trimming from the field.

If you have ten hands trimming, one to pick up 
and put into crates, one to draw crates to washing house, two washers and four tyers, you are prepared to harvest from ten to sixteen hundred dozen per day. If you have your packing room iced as it should be for summer, you will not need to hurry it so fast, as a full load for a twenty-four thousand lbs. capacity car is only about three thousand dozen, and as a general thing a dealer can have his celery shipped that way, in one-third loads, and compete in price at that with express. During warm weather they usually only order partial loads. These cars are built with an ice chest in each end to hold one ton and a half each of ice, which will last for a run of six or seven hundred miles in warm weather. Have car iced a few hours before commencing to put in the celery. The boxes for shipping celery in this way need not be so strongly made as for express.

There is a demand for shipments of large quantities in portions of the country where there is but little of any kind grown, as Missouri, Kansas and Iowa, also Tennessee, Kentucky, Virginia, the Carolinas and New England. In most parts where it is grown at all, it is very poor, stunted, tough and uninviting.

But few people know what good celery is yet, never having seen or tasted it. I learn this fact from the voluntary testimony I get through the 
mails from my patrons all over the country, in the manner they express to me their surprise upon seeing such fine celery as shipped from here, and in their comparison of it with what they have been selling. The new order of things that has been brought into existence recently in this vicinity is a move beyond the conception of the oldest grower or dealer upon the continent. To see is to be fully persuaded. Market gardeners have seen it in their markets in many States, and they are so far behind that they track it up and find where it is grown, so as to get the points necessary to compete. "Thus is this age improving upon the age that went before."

There is still another way to ship, that is, by a way refrigerator line which is now in operation upon many of the roads; that is, a refrigerator car stops at all stations two or three times per week and carries all perishable goods in that car at regular freight rates, so in case you are supplying any house upon such lines, it is a sheap way of transportation.

TAKING A REVIEW, AND MAKING AN ADVANCE AFTERWARDS, AND GETTING SOME STOREHOUSE MATERIAL READY.

Now you have your markets established and are harvesting the crop as it ripens, washing it clean, 
preparing it for the market in as good shape as you can, and learning each day by experience. Keep right on doing that way. The growing season is short, and the work must all be kept right up even, so as not to have anything to do in the month of October which can be done before, as that is a very busy month.

It will pay you well in the long run to put a fair share of your crop into store for winter, as the demand for it is more extensive thin at any other season of the year. If you quit furnishing your patrons as soon as winter comes, they will not like it, as they will have to go without for the rest of the season in case they can not find some one else to supply them, and the next year you may fail to get their custom for fear of being again left. Then again, by storing the season is made longer, and the work can be done with less help, and the help) is much better satisfied, as they have a chance to work more months in the year. Bear in mind that expense of storing is light in comparison with the benefits derived, inasmuch as you have the lumber (in the blanching boards) already upon the ground.

You will have to secure another set of hands for taking up and putting the celery into the storehouses, so much of it as you are unable to get into market by the first of November, as that is the rery latest that it will do to have any of it left outside. 
It sometimes is hurt by freezing, even before that date. It cannot stand a lower degree of cold than twenty-eight after it is ripe without serious injury. Therefore, if you have a large acreage you will need to be ready to put some in by the middle of October.

Make arrangements in the spring before setting out the celery, for a site for the storehouses, or at least a part of them. Get them as near the wash. house as you can for convenience in cold weather. You will need tu cut in time coarse grass, wide blades, enough to corer the roof of the storehouses eight or nine inches in depth, and have it stacked liandy by. In case that cannot be procured, straw or chaff can be used. Now for poles to support the roof, and posts to support the poles. Have them also ready, then they will be seasoned and light to hinndle. Straight poles are the thing, from three to five inches in diameter. Peel them while green. Tamarack or spruce make nice ones. In case you cannot get poles, use scantling four by four. The posts can be made from material of any kind, so it has the strength.

Perhaps the first year that you are in the business, you would not care to make rery extensive arrangements for storing, but it would be best to put up one or two storehouses anyway for the experience afterward. 
BANKING WITH EARTH FOR BLANCHING, ALSO AS A PROTECTION AGAINST THE FREEZING WEATHER.

The first of September it is safe to commence throwing the earth up to the rows of celery with a view to blanch it. Consequently all that you have at this date (which the boards will not have time to blanch and still be ready for use in the storehouse construction by the first of October) which you do not want to save for winter use and put into the storehouse, needs now to be banked gradually along during the next twenty days.

The Planet Junior Cultivator is the first tool to use. Set the two side shovels or wings at an angle to throw the earth towards the rows; have on the large rear tooth in the center; go through between all the rows to be banked, once in a place, then turn back and go once in a row in the opposite direction, bearing down hard. This work shoves the earth up to the plants, and under the leaves.

Now be it understood, there is no tool upon the market that will do the banking as well as a homemarle shovel plow shown in plate (see cut No. 12). Although the Planet Junior folks make what they call a celery banker, it is not nuch, if any, better than the cultivator, unless they have improved it since last year, of which I am not advised. That being the case I was forced to make one. 
THF CONSTRUCTION OF THE SHOVEL BANKING PLOW AND ITS USE.

\section{(See Cut)}

First getting the largest shovel plow I could find in the market, I had holes drilled through the top, then took No. 1 sheet iron, ha:l a blacksmith cut a strip six inches wide, and give it at the ends the same slope the shovel has, and put three holes through to mate those in the shovel, and bolted on. You can see the whole construction by looking at the cut.

When that was done it was not high enough yet; the earth would roll over the top, so I had another six-inch strip) bolted on. It, is now firstrate. The plow shows a flat front, but it is not so. It is nicely rounding so the earth rolls from it, and is crowded towards the rows and left just where you want it.

This plow follows up the cultivator after the second time through, the rear tooth having loosened up the center of the row. Now the shovel plow will roll that earth up towards the rows. But as it is early, and no danger of freezing weather, and it may be hot and wet enough to rot or rust the stalks in case the earth is thrown too solidly against them, hence the plow should be handled by a strong careful man, and the carth gotten just as close to the stalks us it can be and not rest against them, the lower 


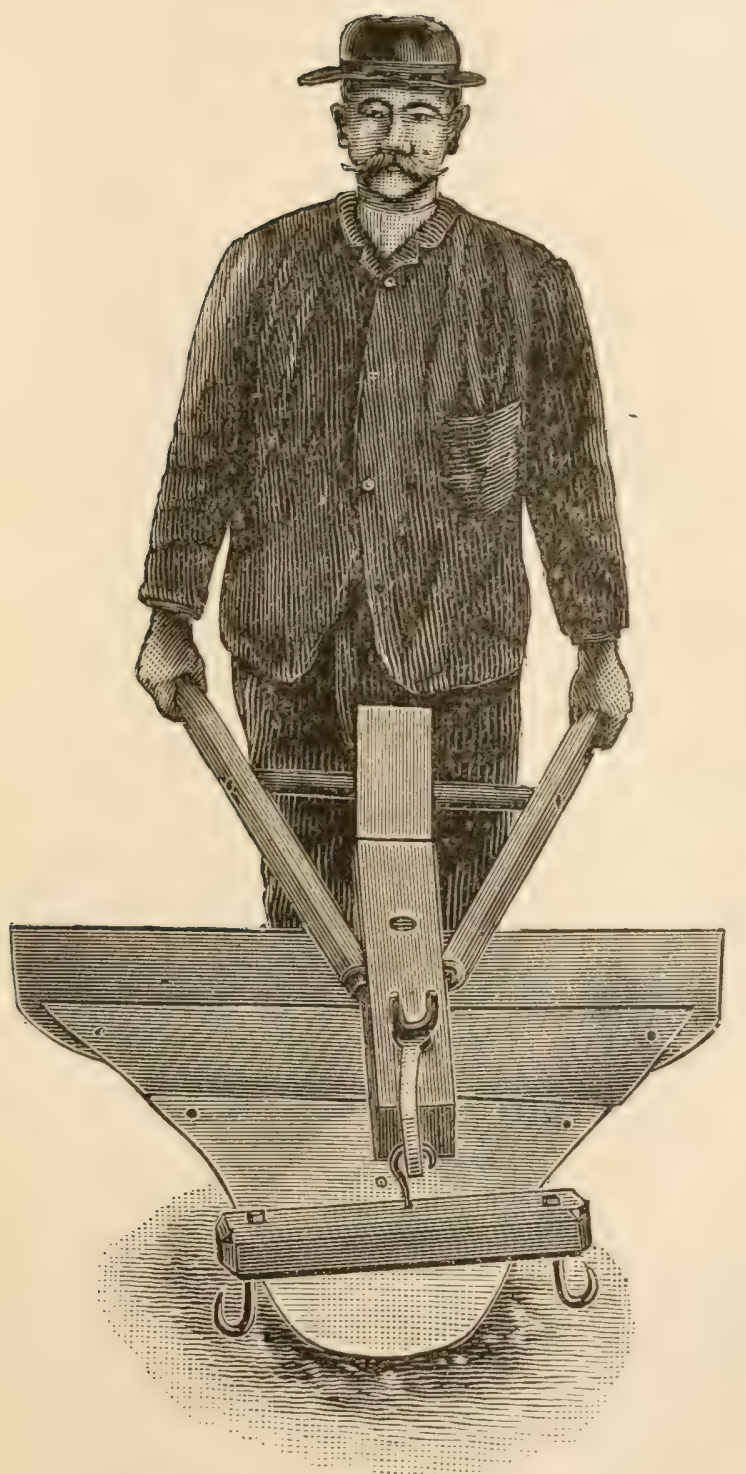

BANKING PLOW. (Cut No. 12) 

leaves being so thick that they will help very materially to keep the earth from the stalks.

By treating it thus, in four weeks, with usual S'ptember weather, it will be prime. If your celery is large, you may need to go in the row twice. If so after once through with the shovel plow, go once in a row with a two-toothed corn cultivator, such as is in common use. That loosens up the bottom of the row for the shovel plow again. This shovel plow also brushes back the leaves with the wings. In case the upper addition is not needed, take it off. You can also shape the curve of it just as it needs to be act right upon the soil.

It takes a few days longer for it to blanch than it would if the earth were rolled against it, which it will not do to have done earlier than the twentieth of September. Again, the celery will be cleaner, consequently not so much work to wash it. Have the frame of the plow made just the height that it will be easy to put your weight upon it, and it will require it frequently.

A plow like this is just the thing to hill potatoes with, when grown upon these peat lands, as it leaves a chance for them to breathe through at the sides, and drains them a little in case of too much wet.

I had nearly iorgotten to say that there are only tro kinds of celery that will blanch with the earth 
as here advised. Those are White Plume and Golden Self-Blanching. All other kinds nust be banked tight but not so early within a few days.

THE TIME FOR BANKING WINTER OR STORE CELERY.

All of the celery that is to go into the storehouses for winter market must be banked a little at least, in order that the stalks may be pressed together and so form a close, symmetrical head; partly for the sake of appearance, more so it can be handled without being badly broken to pieces while being harvested. It would be all sprawled out if not banked, and the stalks badly broken by handling. Some get broken even at the best.

Now this storehouse celery should be banked between the twenty-fourth of September and the first of October. Go through twice with the cultivator and once with the shovel plow. That will be enough at first, in case the ground is mellow so you can throw the earth against the stalks twelve inches high. If not loosen up the bottom and go through with the shovel again.

North of latitude $42^{\circ}$ do the work a little earlier, and south some days later (according to the distance) than dates given here. The routine of work and the principle connected with it are just the same both north and south, but the seasons are shorter north, consequently the celery could not be 
put out so early in the spring, and would need to be all secured earlier in the fall. Each one must decide for themselves according to the latitude in which they live. In south latitude it is all earlier the farther we go. When we reach the Gulf States, the plants do not want to be set until the last of October and through November in order to get the growth in our winter; then we can commence harvesting the middle of January, and carry itinto April. There is no need of storing there, as it is a very rare occurrence that frost would hurt it.

Twelve inches is high enough to bank, unless it is to protect it from freezing, which must be thought of, as sometimes it gets quite cold by the middle of October. By having the ground loosened between rows, when cold is threatened the only safe way is to go through with the shovel plow and raise the earth right up on to the celery as high as you can, so the frost cannot work down the stalks.

Celery that goes in store, that you expect to keep until New Year's, need not be blanched more than ten days; for if allowed to get much ripe, it will not keep long. The White Plume and the Yellow is not to be depended upon after New Year's, as it does not stand the storehouse confinement as well as the green sorts. All kinds will blanch in storehouse if kept long enough, even if put in green, providing the roots stand upon a damp bottom so 
that new rootlets will start. Evolution must take place in order to get a nice bleach. The ends of all the rows must be banked with a hoe or shovel, as it cannot be done complete with the plow.

AN ATTACHMENT FOR A ONE-HORSE PLOW TO CUT OFF THE ROOTS, AND HOW TO USE IT.

(See Cut No. 13.)

So far the roots have been cut with the spade when harvesting, from the fact that it does not do to cut much ahead of its being cared for during warm weather, as it wilts so readily. But now with the approach of cool and cloudy weather, this advance will be in order.

There is no plow with this attachment in the mirket, although I will try and have one put in by the Planet Junior people. Therefore proceed as follows: Take a common light one-horse plow, and drill two holes 11 the land side, at the rear end, one inch from the bottom. Have the holes about three-eighths inch in size, for two bolts with easy working burs. These bolts are to hold the knife in position as you see in cut. Now have two knives made of the best steel, and have the blade curve to the left of the land side about forty-five degrees from a straight line with its shank and mold-board, when bolted together. The blade is to be about twelve inches long by one and a half wide, and a 


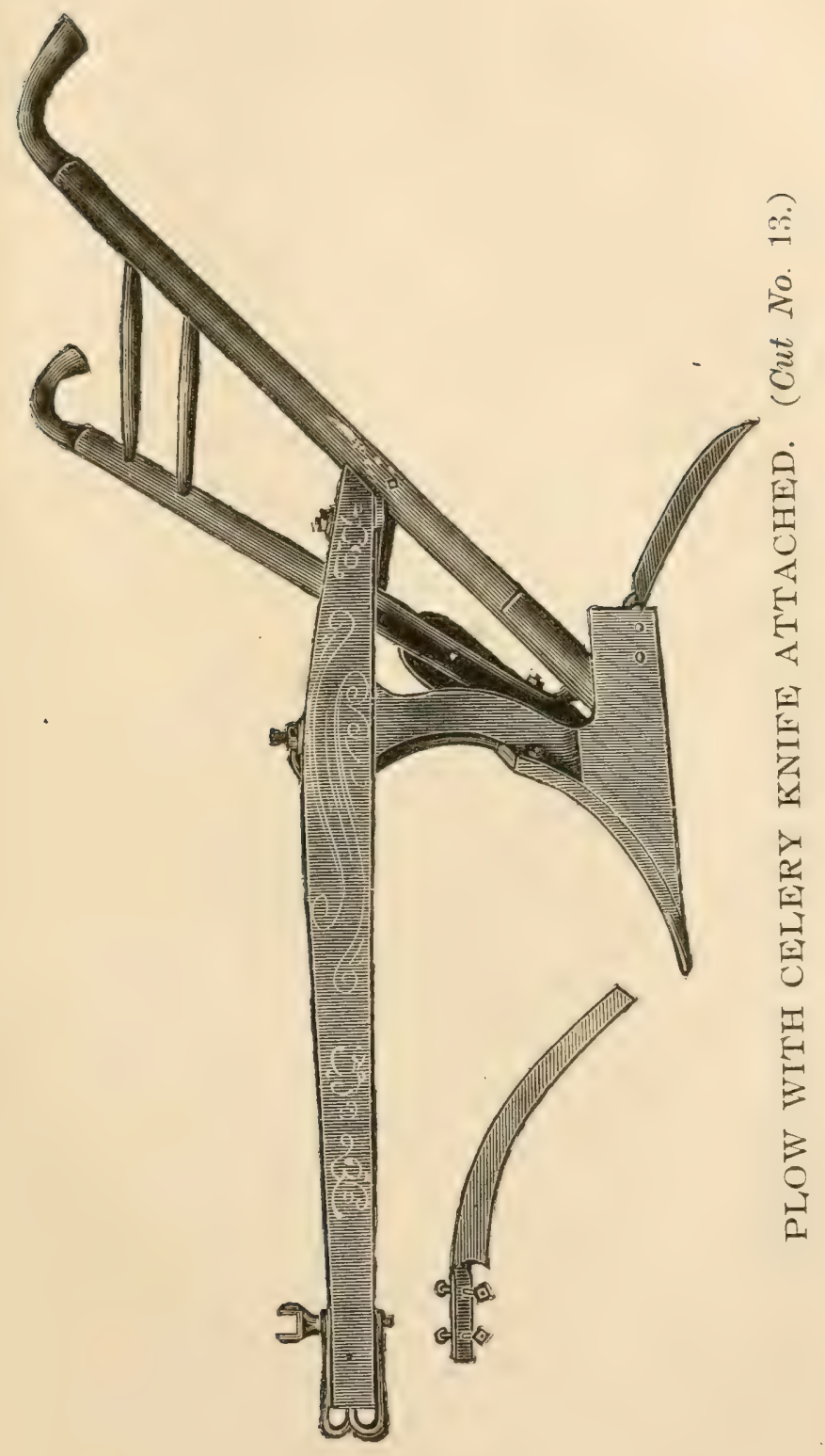



little heavy at the shank, just in the angle so as not to break, and the blade as it leaves the shank set snug to rear of the mold-board, so no clog'ging can take place at that point. The blade can be thin, scant one-eighth inch. The slant that it has bickward will allow it to clear itself from any obstruction that it may come in contact with when in motion, by sliding around it. Made as advised, it will cut eight inches to left of mold-board and at just the depth you hold it under ground, when in motion. The beam needs to be turned so that it will run to land its full capacity, in order to make it hug to the row (use a short whiffletree, and let the off trace come between the hind legs of the horse), as the slant of the knife when cutting tho roots gives it a tendency to work away from the row, just the same as it would slide to the right when working past a solid snag. Hold the plow firmly, and keep knife sharp with a flat file, and you will be pleased with its work.

It is very hamdy to have two plows, as the bank must be thrown away from the row with the plow by going through once upon carch sicle first, without the knife on. Make the horse walk close to the row. But in case you have only one plow it is just as well, only it gives some extria work, simply in the matter of putting knife on and taking off. By using this cutter you will not need by onc-fifth 
as much help as you will if it is cut out with a spade. Now when you are ready to commence, throw back from both sicles of a few rows the bank of earth that has been thrown up to blanch it. This is done, remember, before the knife is put on. Have a common corn-cutter, keep sharp with a file, have a man follow right up and trim the outside leaves from the row upon one side. This can be done better after the earth has been plowed away from both sides. Then walk close to the row, and with a swinging motion of the corn-cutter let the point slide under the leaves and outer stallis, bringing upwards as you slide it along. Trim from the opposite side of the row, then serve the other side the same way, also taking a little from the height, where it does not interfere with the heart stalks.

Now we are ready to attach the cutting knife to the plow. Spade away from the ends of the rows, so as to see just where to set the knife in under the heads and to cut the roots about three inches long. A careful hand will learn to do it well in just twenty minutes. You want to go once upon each side of the row after the cutter is attached.

HOW TO HANDLE THE HEADS THAT ARE 'IO BE STORED.

Now the heads of celery are ail standing in the 
rows yet, but take hold of one and you see it is loose at both sides and the bottom. In case this is to be trimmed for market, do it the same as if cut out with a spade. But if it is to be put in storehouse, take out one head at a time, leare upon each a ball of earth the size of a goose egg, and break off with your hand.s the outer stalks, then lay in little piles of about six hearls cach, so they can be easily encircled within the grasp of the two hands and stood in a box such as heretofore mentioned: that is, thirty inches long, twolve high and the same in width, bottom and ends three-fourths inch, but side of three-eighths or onc-half inch. Stand box at a slant endwise with one end down in the furrow, now fill with the heads; they will lay in nicely without breaking the stalks or mutilating the heads.

Give particular attention to the way each hand does his work, as this process is very prolific in broken stalks. Firmly insist upon having each head handled with care. When taking out from ground, grasp head near the roots. When the heart stalks are broken, the beauty of the head is spoiled. When stripping off the outsicle leaves, hold the root uppermost, so the earth will not work down between the heart leaves, as that makes extra work washing: When handling the boxes 
filled with celery, loading or unloading, do it with ("are, so as not to chafe stalks upon sicle of box.

BUILDING A STOREHOUSE AND VENTILATING THE SAME.

Now we must build the storehouse, and will commence by clearing the site of obstructions, and staking off twenty-eight feet wide by about one hundred feet long. Stand long way east and west. Take common box scraper and scrape out the earth from between the stakes, and dump it on a line between the stakes, rumning the long way. This is for the eares of your roof boards to rest upon, and the excavation will need to be about six inches decp to get earth enough to make the bank three feet high. In case it is soft mellow land, anything like part, fire hours will do it good.

Now stretch a line from one stake to the other three fect above the ground, and square the west aind of the storchouse to the line. Drive stakes three inches in cliameter three feet apart along the whole distance and decp enough to hold the bank. Three feet will be enough in almost any kind of ground. Now back up the stakes with boards. In case of any loose earth being inside, shovel back of boards so the earth floor will be level. Build at first two boarch high, then drive down the boards so the bottons will be about level with the earth floor of the house. Put on boards to make it three feet 
high, fill in solid against the back and tread down, then build up the earth six inches above the upper edge of the line of boards, the whole length; lay six inch strip whole length on top for the eaves of roof boards to rest upon, so they will settle even, thereby leaving no crack for the cold to get in. Drive all the stakes down even with upper edge of boards; now secure the other side the same way.

This kind of a house is only temporary, put up any where in the celery field that you want it, and taken down in the spring. The same lumber is used for blanching boards in summer.

Now set posts through the entire center to hold the ridge pole. Have them ten feet high in the clear. Dig a hole two feet deep, into which stand one for the end of each pole or scantling. In case the ground is soft at the bottom put in a piece of plank for it to stand upon, then stand supports in between, enough to hold the roof. Remember it will be quite heavy. Now the next thing in order is to stand some boards along upon their edges upon the ridge pole and eaves rest. Draw a line through for a guide by which you can put a support midway between the ridge pole and bank at eaves. Put up the same style as in the center, only give more strength as the weight will be there.

WTe are now ready to put on the first course of boards, having finished with them for blanching 
for this year. Let the first boards come just eren with their supports at the west end; put one No. 8 nail through the board into each of the three supports at the peak, center and eaves. Start both sicles of roof. Now lay another board close up, nail at the ridge pole only. The next boari nail same as first and so on all the way through. It makes it plenty strong, and they are very easily taken down in the spring, which is better than working around them. You can build permanent ones if you think best, by nearly the same method, only they had better be built a little higher, as the higher the better ventilation, hence the better and longer the celery will keep.

There is one thing I wish to call particular attention to, that is, the rentilation. By leaving a ten-inch space at the peak upon one sicle of the center, the whole length of the building, a twelveinch board will cover it lengthwise in time of need. The way to do it is this: Let every fourth board go on to the ridge pole, holding ends of those that do not come up, with a strip supported lyy brackets on center posts; nail to the rilge pole and at all points; then they will hold the boards when the ventilating hole is to be covered. We are now orer it once. Go over it with another course. Let the first board on the west end lap over six inches, then the center of the boards of the second course 
comes just over the cracks of the first course every time. Finish all in the same manner.

One important item I har nearly forgottenthat is, put in a hothouse sash upon the south sile for light and ventilation every twenty-five feet. Have the upper end at the peak. Let it be in a frame or curb, with curb boards ten inches wide set right into the first two layers of the roof, with cleats nailed in a little below the upper edge, to rest the sash upon. Now this roof is done until cold weather approaches. Then put on evenly all over the roof about eight inches of marsh hay, or its equivalent; then two more courses of boards, same as first. The weight will settle the hay down so the roof will be about even with the windows.

It is practicable to lengthen out the storehouse to the east for one hundred feet more when needed, in case you want to do it, making it two hundred in all, but it is much more convenient in storing the celery to commence at the west end and add to its length as you fill. I make mine in the way described, and have never had one spread, nor blow down, nor get out of shape, nor celery freeze in the winter with the thermometer seventeen degrees below zero.

Before commencing to store, jut a twelve-inch wide board at the west end, the lower edge resting upon the floor where the celery is to stimd. This 
board is permanent. (Leare a space in the center of gable, about four feet wide, to wheel the colery boxes through.) Nail them to the outside gable end posts put in the ground, that come up and are nailed to the roof boards, under side just flush with the outer edge of the first bottom board, they being the frame for the gable end. This spare of four feet left to take the relery through must have louble doors as cold waather comes on. The rest of the space is to be boarded up, nailing to the studding except twenty inches down from the edge of the first roof board nailed on. This space must be twenty inches down all the way from the eaves upon both sides to the peak. Have the gable end boards sawed at a slant, so the space will be true. After the house is filled it can be finished this way, but not until then, as it is not so handy nor airy when filling. Both ends are to be fixed this way. They are to rentilate by letting the wind drive through, whenever there is a day that it will not freeze. It needs no door in the eist end.

After the celery is in, and there is danger of freezing weather, bank up the gables with earth or coarse manure. This trenty-inch space is to be closed with two boards upon carch side of eenter post, by sawing the ends at a slant to fit at the center, and a little chamfer at the lower end. Sixteen feet long by twelve inches wide are the ones. Let 
the lower edge lap over a little upon the gable boards already on, and tack fast to posts. Now one more board above, upon each side, smug up against the sceond course of roof boards and tacked to the elge of the first roof board, makes a tight finish. They are easily and quickly put up and taken down, and it is enough generally for Norember weather, by laying off the sash and peak-ventilating boards, which can be off unless it is storming when real cold. The ends will freeze much sooner, but by giving it close attention you will soon learu just what to do and when to do it.

Bear in mind to keep it ventilated cvery hour you can consistently. A great deal of celery ruts in the storehouse, by not being properly rentilated. It is very bad to have the moisture condense upon the leaves. So long as you can keep them dry you are on the right road, and the gable end circulation is fine for driving out the vapor.

PUTTING THE CEIARY INTO THE STOREHOUSE.

Now all is supposed to be in readiness to commence placking it away. In drawing the celery use platform upon wagon only. Set full one course. Never place one box upon another. Drive right to the west end. Commence and carry the boxes inside, while filling near the end, but as the work gets farther away, load the boxes about three 
at once upon the wheelbarrow, and wheel to place. Now stand ten-inch boards edgewise and supported by a stake, fifteen inches from the wall, upon both sides of the building.

Commence at the west end. One man sets the boxes aiong the line of the partition board, another hand does the packing, by taking out two or three heads at a time. Stand first snug against west end hottom board, straight "l). Go right along, pressing each new lot put in close to what has gone before, accasionally using the heel of the font to compact the roots, striking close to the ground, standing with back to celery while packing. Have each head stand straight, or when it is trimmed out it will show a crooked, unsalable appearance.

Finish the rows right through to the east end, and is you get past the center unload at the east end, it not being so far to wheel the celery. One packer can work in each sparce, and at each end in case of a hurry. When filled space off fiftecn inches more, and stake another row of boards same as first. Now fill with celery. There are now two rows of boards and stakes to hold them. These stakes are to be used orer and orer, for all the house. Now measure ofte fifien inches more, take the stakes from the first row to hold them up. Now that first row of boards must be raised up. Standing in the space for the third row, rearh right over 
the second row, grasp the first row of boards, one at a time, raise it so the upper elge will be eren with the height of the celery. Where the board was, is now an open sprace for the air to circulate through, orer the entire storehouse when fillerl. Serve all the sime way. The pressure of the ("elery upon each side of the board raised will hold it in place after being so raised. In càse it should not, place short sticks under boards to help sup)port.

Keep right along just as advised, working towards the center, until there is only a space of four or five feet remaining. Now you will (as a matter of convenience) commence midway and work out toward the ends, filling the entire space left as you go, unless you leave twelve or fifteen inches for an alley-way through the entire length, which is quite handy in case of examining the condition of the celery from time to time until trimmed out. Each box as emptied is turned over by the packers, so the earth jarred from the roots is left upon the floor of the storehouse.

I have made the west end of the storehouse a starting point, simply because it is necessary to have one, but it can just as well be the cast. They should stand the long way in line.with the prevailing winds, so as to get that draught through by the way of the gable ends, to drive out the vapor which 
is so detrimental to the well-being of celery in store.

One hundred feet length of storehouse will hold about twenty-eight thousand heads of good growth. Never put the celery in wet, as it will not keep. Always have it dry, and pack just snug enough so that each head will stay in an upright position.

Have one permanent storehouse built somewhere just at the edge of the field out of the way. Use this one for your hothouse in the winter. You will find it very liandy. The roof boards can be used every year for blanching purposes just the same.

Don't disturb celery in the least when the leaves are frozen, as it will make it rot. Wait for the frost to get out entirely.

Don't neglect the ventilation of the storehouses, as their contents are very valuable. The ends should be open all the time, except when in danger of freezing, and the roof ventilators must be closed in time of storm. The ends will need to be closed also in case of a driving storm. Have drawn at the ends, for a case of emergency, some coarse manure, so as to throw up against the gable ventilat. ing boards in event of a very cold time. Then just as soon as it passes, open up again in full.

After the last tier of boards is upon the roof, bank up well the ends of the boards with earth, 
letting a few inches of it come upon top of the last course to hold them down and keep out the cold. It will not obstruct the water from the roof to harm anything in the least. The roof over the hay does not need nailing. A row of rails laid the whole length, near the peak, will keep the boards in position.

\section{TUCKING UP THINGS FOR WINTER.}

The prospect of cold weather is drawing near. Some things need attention with that in view. All water pipes that are exposed need to be wrapped either with sacking; building-paper or old carpeting. Make a final clean-up of all the celery that is out of doors on or before the first of November, as one cold night now with the thermometer twelve or fifteen below freezing will seriously injure all the exposed portions of it. Before it freezes up, level down the celery ground, as where you have harvested by the use of the plow it is in ridges, and would not be in good shape for the distribution of manure over its surface the ensuing winter.

Have it only just comfortably warm in the washing room, as it will generate too much steam, and the hands will be liable to take cold when going out into the open air.

Rochester lamps are the kind to light the wash- 
ing and packing rooms with; as the days are now getting so short, evening and early morning will be dark. There will also have to be limpls in the storehouse when trimming out of there.

An office building is a necessary adjunct, close by the celery buildings, with telephone, so as to get your telegraph orders as soon as sent you, also orders by telephone from places near by. Your general celery business will be transacted here, such as noting the time of help, debit and credit of your patrons, correspondence, etc. It will bu a busy place during harvest, especially in case you have a telephnne, which you need in an extensive business.

TRIMMING OUT FROM THE STOREHOUSES.

After you have been supplying good customers for a time, they do not like to be disappointed in not recoiring a supply of celery when they expect, as that disappoints their patrons also. You may lose a good house through disappointing a few times. Therefore in storing celery, put that of different grates of ripeness in louses by itself, so it will come out uniform. Have one that will be ready to commence upon as soun as the last is trimmed from the field. Start a man or two at it at first, and open up at the entrance from the lnor, then work across the entire end, and take cleam as you go. The partition boards will come out to better advantage. 
When making a start upon a new storehouse, in case the weather is mild enough so it will not freeze, take right outside and trim until you get a start. After getting the colery all trimmed out, pile up the leaves, and they will heat and rot down. The houses can be taken down in the spring, after the snow goes off. Pile all the lumber with a cover, wired down.

\section{MAKING THE FINAL CLEAN UP.}

See that the well to the windmill is covered with coarse manure, so that none of the pipes will freez'; also that the permanent storehouse to be used for a hothouse does not freeze. Now, after the list box is marketed, pick up all the tools and put in their places, that nothing may be lost or wasted.

All who want only to grow celery for their own use, can pursue the course laid down in this work upon just the scale their wants demand, and for winter keeping store in out-dloor cellar, or boxes, or half barrels, or upon the bare ground in the cellar, with water turned upon the roots occasionally, especially if the cellar is dry. Use a funnel to run the water on to the roots so as not to wet the leaves or stalks, as it rots them. Those who grow celery for their own use can afford to give it extra care. Give it the choicest place upon the farm or in the garden. Make t? 
land very rich. Keep watered in a dry time. Don't bring the earth to it until late in the season. Blanch with boards, tile or paper, that which you want for use in warm weather. A part of that which you want to keep until into April and May, don't blanch at all. Bring up the stalks in a close upright position (before taking out of the ground) and tie with a cord. Stand away in a cool cellar, or out-door root-house, and they will be fine just when it will be difficult to find it in the market.

In writing this treatise, beginning with the selecting of the grounds, by thorough description, and carrying you along step by step through the prospective crop, I beliere I have noted every essential point upon which rests the culmination of a tinal grand success. Therefore, trusting that you will, when growing your real crop, follow up and atopt each principle as adriscd, in a carcful and lainstaking way, with the same zoal and carnestne:s with which I have endeavored to write it, a triumph will have been attained, a success assured, and a resting point in life's journey reached 
THOUGHTS AS THEY HAVE OCCURRED SINCE WRITING THE BODY OF THE BOOK.

There are several items of interest and worth, which I did not think of until after the book had gone to press. They will now come in under the above heading.

First. Allow no decaying substance of any kind near where your celery is stored, for-if you do the celery will taste of that substance, consequently hurt, if it does not entirely spoil, the sale of it. Whenever the air is offensive to the nostrils, give it attention, as the celery stalk is so juicy it will take it up and hold it. This very thing cost me one hundred dollars. In the early days of my growing celery I lined the outside of one end of my storehouse in part with common tarred building paper. It was there about thirty days when I commenced trimming it out for market, and for fifteen feet in, it all tasted just as if kerosene oil had been turned upon it, would not sell, and it also hurt my trade for trying to sell it, which I did not do after I found out it was barl; yet it was hard to explain away the bad taste. Some thought its bad flavor came from ny trying to blanch it in some way chemically, which was purely imaginary ; but it was one of those schools of experience to me which the immortal Noah Webster used to talk about in the old elementary spelling-book which was used in 
the schools in Michigan in the early days. I have never been caught that way since.

Celery rust, as applied to the stalk, is simply incipient decay, but as applied to the leaf it is an entirely different thing. The lower leaves will commence to die and turn brown, the growth of the plant stop, and it is practically spoiled, usually affecting the entire foliage of the plant within it few days. It rarely affects young plants, but they are half or full grown before it appears.

It is not often that celery is affected in that way, and there is no known reason for its appearance. It is just as liable to come in a wet season as a dry, upon poor land as good, upon a wet portion of the field as the dry, generally in patches here and there, consequently there is no known remedy. The cause is simply theoretical. Some horticulturists have rentured an opinion, but my own experiences get around all that I have seen given yet. For instance, one writer thinks it comes from root disturbance, yet I have seen it where there had never been any root disturbance, not cultivated to disturb one root, and the soil perfectly free from insect life. It is probably due to the presence of a mite, too small to have been yet detected, which uncler just the right conditions springs into life in a minute, and upon a change of atmospheric conditions goes just as quickly. I think the con- 
dition could more appropriately be termed a blight than a rust. As yet it has done but little harm.

There is a green worm with white stripes over the back, which sometimes feeds upon the leaves, but so far has done noapparent harm. With these exceptions celery is free from special enemies or pests.

All celery packed in storehouses to come out in six weeks from date of going in, does not hurt if stored just as snug as you can pack it, in case it is put in dry and kept well ventilated as heretofore advised, and as the room is valuable, that is the proper thing to do, but bear in mind the longer it is to be kept the less crowded it should be.

The trimming off the leaves with the corncutter, except the heart leaves, as heretofore advised, requires your best attention, as that allows the air to circulate more easily through between the heads, as well as relieves it of that part which rots first, and afterwards affects the stalks by forcing upon them bad company. Another view of it is this: In case there was no value in beauty to the leaves of the heart, then all the leaves could be stripped off and the stallis would lieep indefinitely. Hence the value of taking off all that can be judiciously spared. When the leaf rots, the stalk takes up the odor of decay, consequently it becomes very nearly worthless. 
I have been véry much surprised to see the amount of celery rot in store from being put in with too much leaf, and so poorly ventilated, which aro the general causes of the loss, and by growers that had grown gray in the business and certainly ought to have known better.

Don't let your early plants get stunted from cold or drought, as they will go to seed just in proportion to the check back that they get, and all of that kind are worthless. Do not allow a head which shows an inclination to go to seed to be put up for sale, for it is a fraud and will militate against you in time, as the stalks are strong and tough and not fit to eat. That lind of a head shows an extra thickness at the heart just above the root, at which point the stallis show great irregularity in coming out. This is the case where the seed stalk has not grown out fir enough to show what it is at a glance, and some growers (I am sorry, to say) excuse themselves thus for putting them into the bunches for sale. There is quite likely to be occasionally a head here and there through the ficld going to seed. You must expect that, and there is no remedy. Keep thrift in the plants and you will have but few of that kind.

In the selection of a site for growing celery, if you hare a piece which will work easily and is moist, that is the piece even if it is ever so poor, 
because you can enrich it to the very highest state of fertility. If the ground will give the plants drink and hold them in position so you can feed them, that gives you one of the best of chances. I had one acre, where the corn only grew two feet high and no ears at all, the land was so poor from some unaccountable cause. It was new, had never raised a crop. But with double the fertilizers which the rest of the land had, it grew equally as good a crop of celery, and has all been fertilized the same since; there has been no difference since in the production. This acre had one tun of refuse salt, two hundred bushels ashes and fifty loads of barnyard manure. Make the land rich enough at first to produce a good crop, then put on enough each year to hold it right there, and you are working to a purpose, and the results will be highly satisfactory.

Don't make your storehouse warm too early. Iou had better let a little freeze than to hare consiclerable rot. Standing packed as celery does in the store, it camnot frecze, only the tops at first, be it crer so cold, and that will gire you time to close it up. Be a little afraid all the time of having it too close than too open. Stearly cold, night and day, is what drives the frost into a storehouse. Be prepared to sccure it in case such a spell comes on suldenly. Ail you expect to trim out in Novem- 
ber will hardly need the coarse hay and extra roof, in this latitucle of $42,{ }^{\circ}$ although on November 18,1880 , it was $4^{\circ}$ below zero here

I want to say here that the best strain of Boston Market celery seed I ever had, was from D. M. Ferry, of Detroit, Michigan.

In case you ever sow any kind of fertilizer upon young plants, do it very sparingly, or you will injure if not kill them. If liquid manure of any kind is put on, have it weak. My own experience is that all of the special feeds are injurious to young. plants, but nearly everyone wants to try them for themselves before they are fully satisfied. The best thing to do, is to have the ground well supplied. with phosphate, nitrogen and potash, the three essentials to plant growth, in advance, so the rootlets can feed upon them as soon as large enough to assimilate. Then they will take it in at their leisure and not be forced to eat if they are not hungry.

The wheel for punching holes is so arranged that wherever the soil is hard, so that the weight of the wheel is not enough to punch the holes full depth, it can be weighted down with a timber upon each side. Also two men at the rear, one at each side of the cross-bar, to push and bear down as well as to hold the wheel vertical. 
For plowing lands which have never been plowerl, a sulky plow, with a rolling colter kept sharpl hy use of the file, does the hest work, as you cail invert the furrow perfectly; as the colter will rut the glass or shrub roots right through, and no tearing or shoving ahearl, as with the old-fashioned upright colter in mellow soils. In case there are no stones or roots more than an inch in rlianeter, the plow will go right through without a miss.

\section{H. L. Stewart.}

\section{Tecumseh, Michigan.}












\section{LIBRARY OF CONGRESS ||||||||||||||||||||||||||||||||||||||||||||||||||||||||||||

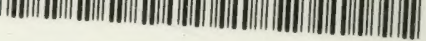

0000916? द A 